\title{
Standardisation and application of the single-breath determination of nitric oxide uptake in the lung
}

\author{
Gerald S. Zavorsky $\mathbb{1}^{1}{ }^{1}$, Connie C.W. Hsia², J. Michael B. Hughes ${ }^{3}$, \\ Colin D.R. Borland ${ }^{4}$, Hervé Guénard ${ }^{5}$, Ivo van der Lee ${ }^{6}$, Irene Steenbruggen ${ }^{7}$, \\ Robert Naeije ${ }^{8}$, Jiguo $\mathrm{Cao}^{9}$ and Anh Tuan Dinh-Xuan ${ }^{10}$
}

\begin{abstract}
Affiliations: 'Dept of Respiratory Therapy, Georgia State University, Atlanta, GA, USA. ${ }^{2}$ Dept of Internal Medicine, University of Texas Southwestern Medical Center, Dallas, TX, USA. ${ }^{3}$ National Heart and Lung Institute, Imperial College, London, UK. ${ }^{4}$ Dept of Medicine, University of Cambridge, Hinchingbrooke Hospital, Huntingdon, UK. ${ }^{5}$ Dept of Physiology and Pulmonary Laboratory, University of Bordeaux and CHU, Bordeaux, France. ${ }^{6}$ Dept of Pulmonary Diseases, Spaarne Hospital, Hoofddorp, The Netherlands. ${ }^{7}$ Pulmonary Laboratory, Isala Hospital, Zwolle, The Netherlands. ${ }^{8}$ Dept of Cardiology, Erasme University Hospital, Brussels, Belgium. ${ }^{9}$ Dept of Statistics and Actuarial Science, Simon Fraser University, Burnaby, BC, Canada. ${ }^{10}$ Dept of Physiology, Cochin Hospital, Paris Descartes University, Paris, France.
\end{abstract}

Correspondence: Gerald S. Zavorsky, Dept of Respiratory Therapy, Georgia State University, Urban Life Building, Room 1229 (12th Floor), Atlanta, GA, 30302-4019, USA. E-mail: zavorskylagsu.edu

@ERSpublications

Pulmonary diffusing capacity for nitric oxide is standardised by a panel of experts for use around the world http://ow.ly/TpV1306Yhji

Cite this article as: Zavorsky GS, Hsia CCW, Hughes JMB, et al. Standardisation and application of the single-breath determination of nitric oxide uptake in the lung. Eur Respir J 2017; 49: 1600962 [https://doi. org/10.1183/13993003.00962-2016].

ABSTRACT Diffusing capacity of the lung for nitric oxide (DLNO), otherwise known as the transfer factor, was first measured in 1983. This document standardises the technique and application of single-breath DLNO. This panel agrees that 1) pulmonary function systems should allow for mixing and measurement of both nitric oxide (NO) and carbon monoxide (CO) gases directly from an inspiratory reservoir just before use, with expired concentrations measured from an alveolar "collection" or continuously sampled via rapid gas analysers; 2) breath-hold time should be $10 \mathrm{~s}$ with chemiluminescence NO analysers, or 4-6 s to accommodate the smaller detection range of the NO electrochemical cell; 3) inspired NO and oxygen concentrations should be $40-60 \mathrm{ppm}$ and close to $21 \%$, respectively; 4) the alveolar oxygen tension $\left(\mathrm{PAO}_{2}\right)$ should be measured by sampling the expired gas; 5$)$ a finite specific conductance in the blood for NO ( $\theta \mathrm{NO})$ should be assumed as $4.5 \mathrm{~mL} \cdot \mathrm{min}^{-1} \cdot \mathrm{mmHg}^{-1} \cdot \mathrm{mL}^{-1}$ of blood; 6) the equation for $1 / \theta \mathrm{CO}$ should be $\left(0.0062 \cdot \mathrm{PAO}_{2}+1.16\right) \cdot$ (ideal haemoglobin/measured haemoglobin) based on breath-holding $P_{\mathrm{AO}_{2}}$ and adjusted to an average haemoglobin concentration (male $14.6 \mathrm{~g} \cdot \mathrm{dL}^{-1}$, female $13.4 \mathrm{~g} \cdot \mathrm{dL}^{-1}$ ); 7 ) a membrane diffusing capacity ratio (DMNO/DMCO) should be 1.97 , based on tissue diffusivity.

Earn CME accreditation by answering questions about this article. You will find these at erj.ersjournals.com/journal/cme

This article has supplementary material available from erj.ersjournals.com

Received: May 122016 | Accepted after revision: Oct 262016

Endorsed by the European Respiratory Society Science Council and Executive Committee, November 2016.

Support statement: This study was funded by the European Respiratory Society (TF-2014-24). Funding information for this article has been deposited with the Open Funder Registry.

Conflict of interest: None declared.

Copyright @ERS 2017 


\section{Development and selection of the task force panel}

The initial application to create a standardisation document on diffusing capacity of the lung for nitric oxide (DLNO) began when a proposal was submitted to the European Respiratory Society (ERS) scientific committee in 2014. The proposal suggested that a task force be created to tackle important methodological considerations for the measurement of DLNO so that its measurement and interpretation of the results could be standardised. In October 2014, a revised application was submitted that included a panel of experienced physicians, physiologists, physician scientists and a technologist. In early 2015, the ERS science council and executive committee approved the expert panel and funded the task force. All conflicts of interest were declared and vetted.

The task force panel searched Medline (accessed via PubMed) in a literature search. We used the following main keywords in our search: "pulmonary diffusing capacity", "pulmonary diffusing capacity for nitric oxide", "DLNO" and "TLNO" (transfer factor of the lung for nitric oxide). We combined the results from each of the keywords and then filtered the search to list only human studies published in English between 1946 and 2016. The results yielded 4000 citations. The task force panel then reviewed the abstracts of these citations and identified 103 peer-reviewed articles as relevant to this document, and a further 47 as potentially relevant. Article relevance was determined through panel discussion and consensus. Abstracts from scientific conferences and articles that were not peer-reviewed were generally not included. However, two abstracts [1, 2], a dissertation [3] and a chapter from the Handbook of Physiology [4] were included due to their important historical and scientific significance with regard to DLNO. In all three face-to-face meetings, each panel member critiqued each section for content and appropriate references and debated several issues. This document is the culmination of compromise within the panel.

\section{The history of single-breath DLNO or TLNO}

\section{Origins of DLNO}

Initially, interest in nitric oxide (NO) uptake was toxicological. High concentrations of nitrogen dioxide $\left(\mathrm{NO}_{2} ; 100 \mathrm{ppm}\right)$ or NO $(0.5-2 \%)$ when inhaled for 7-50 min caused death and lung damage in cases of accidental human exposure during anaesthetic procedures [5] or experimental animal exposure [6]. Interestingly an emphysema-like lesion had been described [6], fuelling speculation that "oxides of nitrogen" caused emphysema in smokers.

A group in Cambridge (UK), using an NO analyser based on the description of chemiluminescence [7] found that the half-life disappearance of $1000 \mathrm{ppm} \mathrm{NO}$ in whole smoke was $4.3 \mathrm{~min}$ (adjusting for the $14.4 \%$ oxygen concentration in smoke [8]) and when inhaled, almost all the NO completely diffused into the lungs [9]. This suggested that oxidation of inhaled NO was minimal and that emphysema was not caused by NO.

Next, they measured DLNO and the diffusing capacity of the lung for carbon monoxide (DLCO); these data were initially presented as abstracts in 1983-1984 [1,2], and reported in BoRLAND's doctoral project [3]. Subsequently, these DLCO and DLNO observations on varying breath-hold time and back tension were published in 1989 [10], in which the differences in DLCO and DLNO were undetectable within the sensitivity of the analyser $(1 \mathrm{ppm})$. However, there was greater volume dependence of DLNO compared to DLCO, and independence of DLNO (but not DLCO) from hyperoxia [10].

Independently, Daniel Bargeton and Hervé Guénard in Paris had speculated that the Roughton and FORSTER equation $(1 / D \mathrm{LCO}=1 / D \mathrm{M}+1 / \theta \mathrm{CO} \cdot V \mathrm{C})$ [11] could be solved using a single manoeuvre with simultaneous measurement of carbon monoxide (CO) and NO uptake. DM is the diffusing capacity, dependent on molecular diffusion only, of the membranes separating the alveolar epithelial surface from the red cell (also called the alveolar-capillary membrane conductance), VC is the total volume of blood in the lung capillaries exposed to alveolar air in millilitres and $\theta \mathrm{CO}$ is the number of millilitres of gas taken up by the red cells in $1 \mathrm{~mL}$ of blood per minute per $1 \mathrm{mmHg}$ of partial pressure of dissolved gas between the plasma and interior of the red cell (also called the specific conductance in the blood for CO) [11]. The reciprocals ( $1 / D$ LNO or $1 / D$ LCO, $1 / D \mathrm{M}$ and $1 / \theta \cdot V \mathrm{C}$ ) are the total diffusion (or transfer) resistance and the membrane and red cell or blood resistance, respectively. GuÉNARD et al. [12] published their formula for DM and VC from simultaneous single-breath DLNO and DLCO in 1987.

\section{Evolution of DLNO (1989-2016)}

Early work had shown that mean DLNO exceeded mean DLCO by 4.3-5.3-fold [10, 12]. In other words, the transfer resistance for NO (1/DLNO) from alveolar gas to capillary blood was about one-fifth of that for $\mathrm{CO}$; this difference could not be wholly explained by the two-fold greater tissue diffusivity of NO versus CO. The physiological challenge was to find the reasons for this difference, and to test the notion, originally held, that the specific conductance in the blood for $\mathrm{NO}(\theta \mathrm{NO})$ was quasi-infinite and that the transfer resistance from plasma to haemoglobin $(\mathrm{Hb})$ capture was close to zero. 
Over the subsequent two decades, it was demonstrated that there was "significant blood resistance to nitric oxide transfer in the lung" $[13,14]$, and that $\theta \mathrm{NO}$ was finite. In clinical studies, the fact that DLNO, unlike DLCO, was relatively independent of changes in the inspired oxygen concentration, and thus alveolar oxygen pressure $[15,16]$ and haematocrit [17], which operate through variations in the $\theta$ value for blood, seemed to support the original notion that $\theta \mathrm{NO}$ was "effectively" infinite, and that DLNO is a surrogate for the alveolar membrane diffusing capacity, i.e. DLNO=DMNO=1.97.DLCO; this view is still held by some $[18,19]$. But the current consensus is that DLNO is weighted, but not dominated, by the membrane gas conductance, while the DLCO is dominated by $\theta$ CO [20]. The DLNO/DLCO ratio has been studied in several clinical situations [21]. The uptake pathways for inhaled NO and CO from the alveolus to the red cell in the pulmonary capillary are presented in figure 1.

\section{Determinants of NO uptake}

Reaction of $\mathrm{NO}$ and $\mathrm{CO}$ with capillary blood

The reaction of $\mathrm{Hb}$ in solution with $\mathrm{NO}$ is extremely rapid (nearly 1500 times faster than $\mathrm{CO}$ ) [22]. More importantly, the reaction of $\mathrm{NO}$ with $\mathrm{Hb}$ solutions is $500-1000$ times faster than its reaction with blood from animal [23] or human [24] sources. Therefore, $\theta$ NO cannot be "infinite", as originally thought [10, $12]$ or more recently claimed $[18,19]$. Further support for a "finite" $\theta N O$ value comes from physiological experiments where the red cell was "by-passed", either by adding free Hb (by haemolysis) or a haem-based blood substitute to the membrane oxygenator perfusate, or by exchange transfusion of dogs with chemically stabilised bovine haemoglobin (Oxyglobin ${ }^{\mathrm{TM}}$ ). In every case, DLNO increased as $\mathrm{Hb}$ or its haem substitute became more accessible to inhaled NO [13]. The site of red cell resistance could lie in plasma, the red cell membrane or the interior of the cell. BorLAND et al. [14] altered each barrier in turn. Only changing the red cell interior appeared to alter DLNO [14].

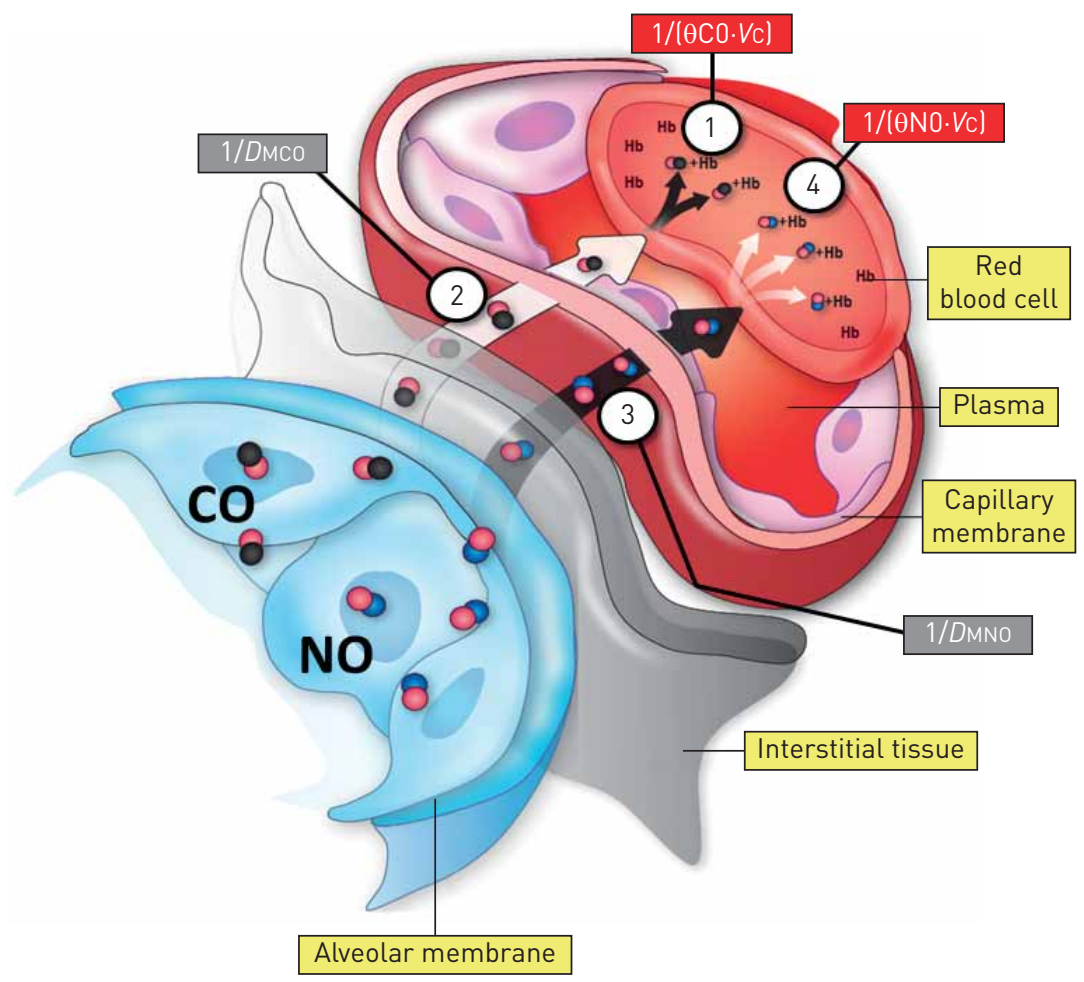

FIGURE 1 Diagram of the uptake pathways for inhaled nitric oxide (NO) and carbon monoxide (CO) from the alveolar membrane to their combination with haemoglobin $(\mathrm{Hb})$ within the red blood cell, in terms of the Roughton-Forster equation, $1 / D\llcorner=1 / D M+1 /(\theta \cdot V \mathrm{c})$, where $1 / D \mathrm{~L}$ is the total resistance to $\mathrm{NO}$ or $\mathrm{CO}$ uptake, $1 / D \mathrm{M}$ is the resistance from the alveolar membrane to the red cell membrane (membrane resistance) and $1 /(\theta \cdot V c)$ is the diffusion and chemical combination resistance (red cell resistance) within the erythrocyte (1). The chief barrier to CO uptake is within the red cell $(\sim 70-80 \%)$; the $\sim 25 \%$ remaining resistance to CO diffusion is located in the alveolar membrane (2). The main resistance barrier for NO lies between the alveolar and red blood cell membranes $(\sim 60 \%$; 3$)$, with the red cell resistance (4) comprising $\sim 40 \%$ of the resistance to NO diffusion, as observed by BORLAND et al. [13]. Specifically, the red cell interior is the determinant part of the membrane resistance to NO [14]. Reproduced and adapted from [20] with permission from the publisher. 
An optimal value for $\theta C O$

Due to competitive binding between $\mathrm{CO}$ and oxygen for $\mathrm{Hb}$-accessible sites, there is a strong association between $\theta \mathrm{CO}$ and mean pulmonary capillary oxygen tension $\left(\mathrm{PO}_{2}\right)(1 / \theta \mathrm{CO}$, the resistance to $\mathrm{CO}$ uptake by blood, increases as $\mathrm{PO}_{2}$ increases). The ideal alveolar $\mathrm{PO}_{2}$ has been taken as a surrogate for mean lung capillary $\mathrm{PO}_{2}$ [16]; the difference is small in normoxia in healthy lungs, but increases in disease due to ventilationperfusion and/or diffusion-perfusion heterogeneity. The relationship between 1/ $\theta \mathrm{CO}$ and alveolar (capillary) $\mathrm{PO}_{2}$ is usually expressed as:

$$
1 / \theta \mathrm{CO}=\left(\mathrm{a} \cdot P_{\mathrm{O}_{2}}+\mathrm{b}\right) \cdot(\text { ideal } \mathrm{Hb} \div \text { measured } \mathrm{Hb})
$$

where the units for $1 / \theta \mathrm{CO}$ are $\mathrm{mL}$ of $\mathrm{CO} \cdot(\mathrm{mL} \text { blood.min } \cdot \mathrm{mmHg})^{-1}$; "a" is the slope, a temperature- and $\mathrm{pH}$-dependent coefficient linked to the kinetics of CO combining with Hb (the "reactive" coefficient); " $\mathrm{b}$ " is the y-intercept, or "diffusion" coefficient (now thought to be mostly within the red cell [14]); and (ideal $\mathrm{Hb} \div$ measured $\mathrm{Hb}$ ) is the standardised normal $\mathrm{Hb}$ concentration as a proportion of the subject's actual $\mathrm{Hb}$ value. Eight published equations (for human blood) have been reviewed in recent publications, but they differ in terms of $\mathrm{pH}$ and rapid-reaction methodology $[16,19,25]$. There is considerable interstudy variation in both "a" and " $b$ " coefficients (equation 1), but methodological differences probably explain most of the variability. For example, ReEves and PARK [26] exposed static, non-flowing blood to step changes of $\mathrm{PO}_{2}$ and carbon monoxide tension; their "reactive" coefficient was 50-90-fold less than found by other methodologies, and their findings have not been replicated. Clearly, differences in the coefficients in equation 1 will influence the calculation of DMCO using the classical Roughton-Forster multistep alveolar $\mathrm{PO}_{2}$ method. For example, upon exercise, and depending on the $1 / \theta \mathrm{CO}$ versus $\mathrm{PO}_{2}$ equation used, DMCO may vary from 48 to $128 \mathrm{~mL} \cdot \mathrm{min}^{-1} \cdot \mathrm{mmHg}^{-1}$ and for $V \mathrm{C}$ from 104 to $212 \mathrm{~mL}$ [27]. In the literature, several versions of equation 1 are used or recommended, notably Roughton and Forster [11], Forster [4] and Reeves and Park [26]. Thus, reported values of DMCO and pulmonary capillary blood volume are inconsistent, although the directly measured DLNO and DLCO should be available for others to calculate DMCO and VC using their favoured different equations.

The dilemma, in terms of which equation should be recommended, has been addressed, in part, by a recent publication from GUÉNARD et al. [16], who tested the published 1/ 1 CO versus $\mathrm{PO}_{2}$ equations for a constant $\mathrm{DMCO} / \mathrm{VC}$ ratio when normal subjects, at rest, were exposed to inspired oxygen concentrations of $13.3 \%$ and 18.9\%. The equations that best predicted an unchanging DMCO and VC, using the one-step NO-CO technique with a finite $\theta$ NO, were Holland [28], Roughton and Forster [11] and Forster [4], but not ReEves and PARK [26]. A "best-fit" optimal solution was given by the equation provided by GUÉNARD et al. [16]:

$$
1 / \theta \mathrm{CO}=\left(0.0062 \cdot \mathrm{P}_{\mathrm{A}} \mathrm{O}_{2}+1.16\right) \cdot(\text { ideal } \mathrm{Hb} \div \text { measured } \mathrm{Hb})
$$

The "a" and " $b$ " coefficients are not dissimilar from existing published values, with the exclusion of ReEVES and PARK [26]. Accordingly, we agree with using equation 2 in this document, since there is insufficient information, at the present time, to choose between the existing published $1 / \theta \mathrm{CO}$ versus $\mathrm{PO}_{2}$ equations derived in vitro.

\section{An optimal value for $\theta \mathrm{NO}$}

Using the same continuous flow rapid mixing apparatus as the 1957 ӨCO measurements [11], $\theta \mathrm{NO}$ can be calculated as $4.5 \mathrm{~mL} \cdot \mathrm{min}^{-1} \cdot \mathrm{mmHg}^{-1} \cdot \mathrm{mL}^{-1}$ of blood [29]. Less direct estimates have ranged from $3.0 \mathrm{~mL} \cdot \mathrm{min}^{-1} \cdot \mathrm{mmHg}^{-1} \cdot \mathrm{mL}^{-1}$ (humans, in vivo; GUÉNARD et al. [16]) to $4.0 \mathrm{~mL} \cdot \mathrm{min}^{-1} \cdot \mathrm{mmHg}^{-1} \cdot \mathrm{mL}^{-1}$ (membrane oxygenator, in vitro; BorLAND et al. [30]) to $<4.5 \mathrm{~min}^{-1} \cdot \mathrm{mmHg}^{-1}$ (dog, in vivo, exchange transfusion; BoRLAND et al. [13]). The consensus is that $\theta$ NO should be taken as $4.5 \mathrm{~mL} \cdot \mathrm{min}^{-1} \cdot \mathrm{mmHg}^{-1} \cdot \mathrm{mL}^{-1}$ of blood. The influence of inspired oxygen concentration (and thus alveolar $\mathrm{PO}_{2}$ ) on DLNO (and therefore $\theta N O)$ is small $[15,16]$, and for clinical purposes, can be ignored. Similarly, the influence of Hb concentration $>5-7 \mathrm{~g} \cdot \mathrm{dL}^{-1}$ on DLNO is too small to matter $[14,17,31]$.

\section{Alveolar-capillary membrane diffusing capacity for NO and the $\alpha$-ratio}

The alveolar-capillary membrane diffusing capacity $(D M)$ is that part of the NO (or CO) uptake pathway where molecular diffusion, driven by the diffusion pressure gradient between the alveolus and the plasma, is the dominant mode of transport. Anatomically, this pathway encompasses the surfactant lining layer, alveolar epithelium, interstitium, capillary endothelium, plasma and the $\mathrm{Hb}$ molecule within erythrocytes under the term blood-gas barrier (figure 1). Physiologically, in terms of the RoughtON-ForsteR equation [11], DM is the $y$-axis intercept, at zero $P_{\mathrm{O}_{2}}$, on a plot of $1 / D \mathrm{LCO}$ versus $1 / \theta \mathrm{CO}$; this definition does not extend to $\mathrm{NO}$, which is effectively $\mathrm{PO}_{2}$-independent [15]. An important determinant of DMNO 
and DMCO is the matching of alveolar NO and CO concentrations to the distribution of pulmonary capillary red cells. Uptake of either $\mathrm{CO}$ or $\mathrm{NO}$ will be compromised if the alveolar capillaries contain few or no erythrocytes. Two major reasons for the increase in DMNO and DMCO upon exercise are 1) capillary recruitment due to increased blood flow or pressure and 2) more homogeneous erythrocyte distribution, which improves the physical matching between tissue and erythrocyte membrane surfaces [32, 33].

The determinants of $D \mathrm{M}$ are tissue diffusivity (a "lumped" parameter for the entire blood-gas barrier) and the pressure gradient between the alveolus and plasma for both NO and CO. Diffusivity for a gas in tissue is the ratio of its solubility in tissue divided by the square root of its molecular weight. NO and CO have similar molecular weights (30 and $28 \mathrm{~g} \cdot \mathrm{mol}^{-1}$ ), but NO has about twice the solubility of CO [34]. The diffusivity ratio $(\mathrm{NO} / \mathrm{CO})$ is generally taken as $1.97[34]$ and is termed $\alpha$. Thus, $D$ MNO $=\alpha \cdot D$ MCO. Until more data become available on $\mathrm{NO}$ and $\mathrm{CO}$ tissue diffusivities in the lung tissue itself, this ERS task force agrees to retain 1.97 as the $D \mathrm{MNO} / \mathrm{DMCO}$ ratio.

\section{An "empirical" value $(\alpha)$ for DMNo/Dmco}

Several groups have measured $D$ MCO using the Roughton-Forster multistep alveolar $\mathrm{PO}_{2}$ method and related it to DMNO (assuming an "infinite" $\theta \mathrm{NO}$, so that $D \mathrm{LNO}=D \mathrm{MNO}$ ). This "DMNO/DMCo" ratio was significantly greater than the 1.97 predicted from the tissue diffusivity ratio $(\alpha)$, and varied from 2.06 to 4.4 , depending on the equation used $[19,25,35,36]$. Even higher values of $\alpha$ would have been obtained if a finite value for $\theta \mathrm{NO}$ had been used. Since $\theta \mathrm{NO}$ has a finite value (and the evidence is overwhelming) this empirical $D \mathrm{MNO} / \mathrm{DMCO}$ ratio $(\alpha)$ merely states the fact that $\mathrm{DMCO}$ calculated from the simultaneous one-step NO-CO method (with or without a finite $\theta \mathrm{NO}$ value) is significantly greater than $D \mathrm{MCO}$ calculated by the classical Roughton-Forster multistep alveolar $\mathrm{PO}_{2}$ method. When recalculating data from a study that used a rebreathing technique [36], with a finite $\theta \mathrm{NO}$ and GUÉNARD's $1 / \theta \mathrm{CO}$ equation (equation 2) [16], the results show that the DMCO from the simultaneous one-step NO-CO method was 1.25 times greater than the DMCO calculated by the classical Roughton-Forster multistep alveolar $\mathrm{PO}_{2}$ method, at rest and upon exercise. With other equations, with or without an infinite $\theta \mathrm{NO}$, the discrepancy was even greater.

With the simultaneous one-step NO-CO method, DMNO could be overestimated if there was significant bronchial uptake of $\mathrm{NO}$, due to its greater solubility, in relation to $\mathrm{CO}$. But the bronchial diffusing capacity for $\mathrm{NO}$ is a trivial fraction of the alveolar NO diffusing capacity in normal subjects. Again, $\theta \mathrm{NO}$ would have to double (to $9.0 \mathrm{~mL} \cdot \mathrm{min}^{-1} \cdot \mathrm{mmHg}^{-1} \cdot \mathrm{mL}^{-1}$ ) to reduce DMNO sufficiently in the simultaneous one-step NO-CO method. One probable reason for the DMCO discrepancy lies in the methods of calculation. Many of the measurements are common to both methods (DLNO, DLCO, $\theta \mathrm{NO}$ and $\theta \mathrm{CO}$ at a nominal $\left.\mathrm{PO}_{2}(100 \mathrm{mmHg})\right)$, but the simultaneous one-step $\mathrm{NO}-\mathrm{CO}$ method uses the diffusivity ratio constant, $\alpha$ (1.97) whereas the Roughton-Forster multistep alveolar $\mathrm{PO}_{2}$ method extrapolates the $1 / \theta \mathrm{CO}-\mathrm{PO}_{2}$ equation to zero $\mathrm{PO}_{2}$ to obtain the intercept (1/DMCO). Experimentally, the $1 / \theta \mathrm{CO}-\mathrm{O}_{2}$ relationship appears to be linear (see figure 3 of Forster's article [4]), but REEVES and PARK [26] found that $\theta \mathrm{CO}$ doubled at $\mathrm{PO}_{2}<40 \mathrm{mmHg}$, possibly due to $\mathrm{CO}$ binding of unliganded $\mathrm{Hb}$ sites versus the $\mathrm{HbO}_{2}$ replacement reaction at higher $P_{\mathrm{O}_{2}}$. Nonlinearity of the $1 / \theta \mathrm{CO}-\mathrm{PO}_{2}$ relationship could lead to overestimation of the zero $\mathrm{PO}_{2}$ intercept and underestimation of DMCO with the Roughton-Forster multistep alveolar $\mathrm{PO}_{2}$ method. It is an area clearly in need of further research.

\section{NO in the gas phase}

Airway uptake of inhaled NO in the single breath hold is negligible ( 0.02\%) (supplementary appendix A). Within the acinus, the dominant mode of gas transport is molecular diffusion. Gas phase diffusion coefficients are inversely proportional to the square root of the molecular weight of the gas, so there is no significant difference between NO and CO. This means that gas phase resistance as a proportion of total transfer resistance (from respiratory bronchiole or alveolar duct to capillary blood) will be greater for NO than for CO, but the effects in normal lungs will be negligible. When gas phase diffusion resistance was experimentally increased using pneumonectomy, a density-dependent reduction of DLNO was observed [37]. There was no consistent effect with DLCO because of its slower alveolar uptake. Gas phase diffusion resistance diminishes as the convection-diffusion "quasi-stationary" front moves peripherally towards the alveoli [38]; a rapid inspiration from residual volume to total lung capacity (TLC) promotes such a peripheral location. Thus, in the single-breath technique, gas phase diffusion limitation of DLNO will be small ( $\sim 5 \%$ of total $1 / D$ LNO) [39].

\section{NO blood uptake is diffusion dependent}

Like CO, the uptake of NO is diffusion limited on the basis of a low, dimensionless $D L / \beta \dot{Q}$ value (the Bohr integral or diffusion/perfusion conductance ratio) where $D \mathrm{~L}$ is the diffusing capacity, $\beta$ is the capacitance coefficient (either the water or plasma solubility or the instantaneous slope of the dissociation curve of gases reacting with $\mathrm{Hb}$ ) and $\dot{Q}$ is pulmonary blood flow (i.e. cardiac output). GiBson and RougHTON [40] 
have published the only known $\mathrm{NO} / \mathrm{NOHb}$ dissociation curve showing near linearity, with a half saturation at $0.2 \mathrm{mmHg}$, therefore $\beta=2.5 \mathrm{mmHg}^{-1}$ and hence $D L / \beta$, or rather $D \mathrm{LNO} / \mathrm{BQ}$ at rest $=150 /(2.5 \cdot 5000)=$ 0.012 . With exercise, the ratio is even lower since the increase in $\dot{Q}$ is much greater than the increase in DLNO. This low value of $\sim 0.012$ (at rest) indicates that the diffusive rather than the perfusive conductance is the rate-limiting step in alveolar NO uptake. The demonstration of a constant DLNO with a 25-fold variation in blood flow in an oxygenator model with a constant membrane surface area favours diffusion rather than perfusion limitation [30].

\section{Blood flow}

Pulmonary blood flow (i.e. cardiac output) increases with exercise intensity. In healthy subjects, there is a linear increase in DLNO of $\sim 16-22 \mathrm{~mL} \cdot \mathrm{min}^{-1} \cdot \mathrm{mmHg}^{-1}$ for every $1.0 \mathrm{~L} \cdot \mathrm{min}^{-1}$ increase in oxygen uptake [40-42], or $\sim 5-7 \mathrm{~mL} \cdot \mathrm{min}^{-1} \cdot \mathrm{mmHg}^{-1}$ for every $1.0 \mathrm{~L} \cdot \mathrm{min}^{-1}$ increase in cardiac output $[35,36]$ (figure 2c). Pulmonary sarcoidosis reduces the slope to $\sim 2.2 \mathrm{~mL} \cdot \mathrm{min}^{-1} \cdot \mathrm{mmHg}^{-1}$ per $1.0 \mathrm{~L} \cdot \mathrm{min}^{-1}$ increase in cardiac output [35]. The increase in DLNO (and DLCO) with exercise is not due to increased blood flow as such, but rather to recruitment of $V \mathrm{C}$ and better matching between tissue and erythrocyte surfaces, and to a lesser extent the recruitment of alveolar-capillary membrane surface area. The correlation of DLCO with pulmonary blood flow is tighter than that of DLNO with blood flow (figure 2c), suggesting that DLCO is more sensitive than DLNO to alveolar microvascular recruitment.

In healthy subjects, inhalation of $40 \mathrm{ppm} \mathrm{NO}$ for $5 \mathrm{~min}$ changed the distribution of blood flow [43], with the redistributed flow favouring the dependent regions. Nevertheless, in terms of whole-body pulmonary gas exchange responses, a 10-min inhalation of $20 \mathrm{ppm}$ NO does not alter oxygen uptake, arterial oxygen pressure, arterial oxyhaemoglobin saturation or the alveolar-to-arterial oxygen pressure difference at rest or during exercise, in either normoxic or hypoxic conditions [44]. In addition, rebreathing NO for $16 \mathrm{~s}$ does not change the measured DLCO or pulmonary blood flow [36].

\section{Back tension}

The endogenous alveolar NO concentration is $\sim 8-20 \mathrm{ppb}$ during tidal breathing [45] and $\sim 100-140 \mathrm{ppb}$ in the nose [46]. The mean \pm SD fraction of NO from a single-breath exhalation at $50 \mathrm{~mL} \cdot \mathrm{s}^{-1}$ is significantly higher in asthmatics $(73 \pm 11 \mathrm{ppb})$ compared with healthy subjects (35 $\pm 4 \mathrm{ppb})$ [47]. Using inhaled NO concentrations of 40-60 ppm and a nose-clip should avoid back tension interference. The presence of NO does not affect the measured DLNO $[10,48,49]$ or DLCO $[10,50]$.

\section{Heterogeneity}

A drawback of the single-breath DLNO (and DLCO) measurement is that the exhaled sample (500-1000 mL) is not truly representative of the actual dispersion of function within even normal lungs. For example, with rapid gas analysers, uneven concentrations of $\mathrm{NO}, \mathrm{CO}$ and inert gases (helium $(\mathrm{He})$, methane $\left(\mathrm{CH}_{4}\right)$, etc.) exist within the alveolar sample, as shown by sloping alveolar plateaus of concentrations versus time or
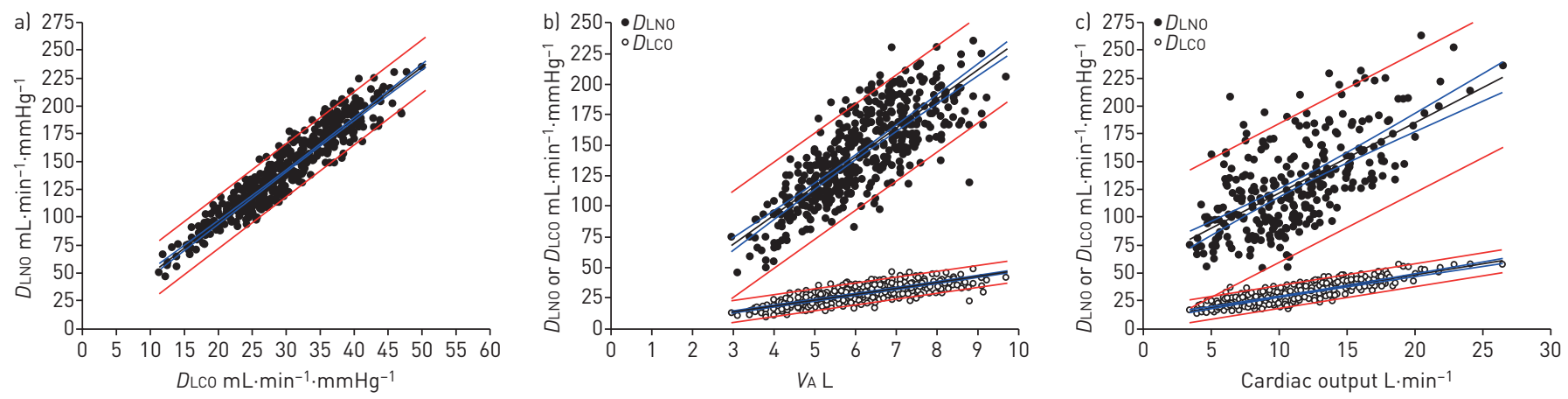

FIGURE 2 a) The association between diffusing capacities of the lung for nitric oxide (DLNO) and carbon monoxide (DLCo) measured at rest (single-breath; average breath-hold time was $\sim 6 \mathrm{~s}$ ). Several published studies were used $[57,106,107]$. $D\left\llcorner\mathrm{LNO}=4.65 \cdot\left(D\llcorner\mathrm{LC})+3.8, \mathrm{R}^{2} 0.90, \mathrm{standard}\right.\right.$ error of the estimate (SEE) 11.8, $\mathrm{p}<0.001,95 \% \mathrm{Cl}$ of the slope $4.51-4.79 ; \mathrm{n}=493$ healthy subjects. b) The association between pulmonary diffusing capacity and alveolar volume $\left(V_{A}\right)$ measured at rest (single-breath; average breath-hold time was $\sim 6 \mathrm{~s}$ ). Several published studies were used [57, 106, 107]. $D\left\llcorner N O=23.0 \cdot\left(V_{A}\right)+2.4, R^{2} 0.64\right.$, SEE $21.9, p<0.001,95 \% \mathrm{Cl}$ of the slope $21.4-24.5 ; n=493 . D L C 0=4.63 \cdot\left(V_{A}\right)+1.55, R^{2} 0.62, \operatorname{SEE} 4.5, p<0.001,95 \% \mathrm{Cl}$ of the slope 4.31-4.94; $\mathrm{n}=493$. All healthy subjects. c) The association between pulmonary diffusing capacity and cardiac output (Q) measured at rest and during exercise by rebreathing. Data from two published studies $[35,109]$, including $\sim 45 \%$ of previously unpublished data. DLNO=6.3. $(Q)+58.2, R^{2} 0.42, S E E$ $31.3, p<0.001,95 \% \mathrm{Cl}$ of the slope $5.5-7.2 ; n=76$, four data points per subject. $D$ LCo=2.0.(Q)+9.0, $R^{2} 0.71$, sEE $5.3, p<0.001,95 \% \mathrm{Cl}$ of the slope $1.8-2.1$; $\mathrm{n}=76$, four data points per subject. All healthy subjects. When using rebreathing manouvres, $D$ Lco is more tightly associated with cardiac output than $D\llcorner N O$ (comparison of correlation coefficients z-statistic 5.52, $\mathrm{p}<0.01$ ); however, DLNo is more tightly related to alveolar volume compared to $D\llcorner C 0$ (comparison of correlation coefficients $z$-statistic 2.27, $\mathrm{p}=0.023$ ). The association between $D\left\llcorner\mathrm{LNO}\right.$ and $D\left\llcorner\mathrm{LCO}\right.$ in relation to $V_{A}$ during rebreathing manouvres ( $r=0.73$ between DLNo versus $V_{A}$, and $r=0.63$ between DLco versus $V_{A}$ ) is not shown here. 

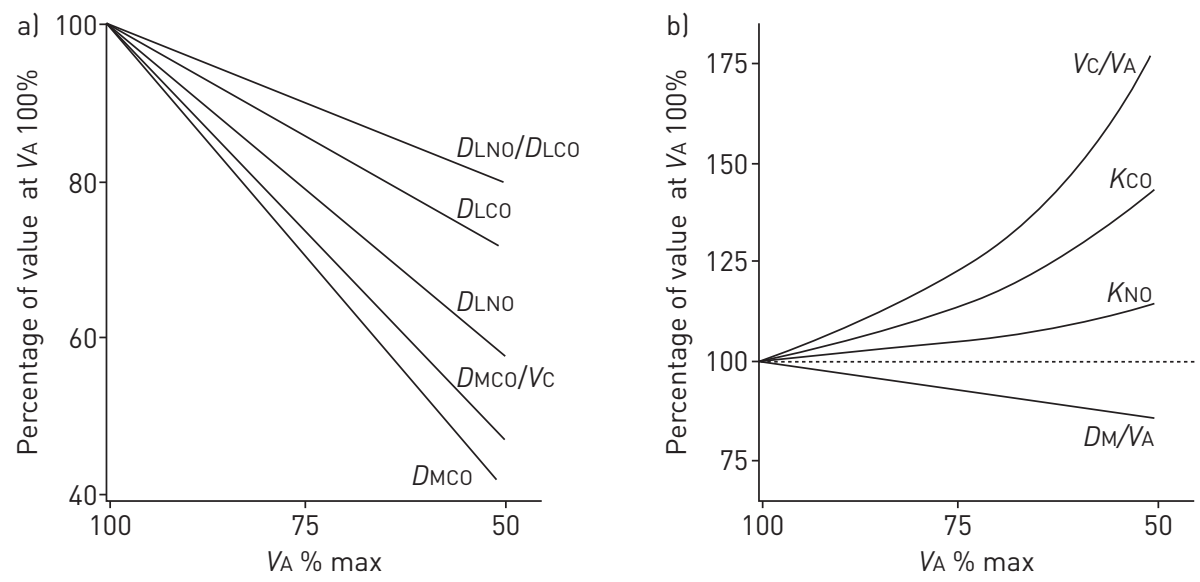

FIGURE 3 Plots of a) pulmonary diffusing capacity for nitric oxide (DLNO) and pulmonary diffusing capacity for carbon monoxide $(D\llcorner C O)$, their ratio $(D\llcorner N O / D\llcorner C O)$, alveolar-capillary membrane diffusing capacity for carbon monoxide ( $D \mathrm{MCO}$ ) and the $D \mathrm{MCO}$ to pulmonary capillary blood volume $(\mathrm{VC})$ ratio $(D \mathrm{MCO} / \mathrm{VC})$, as they relate to the percentage of maximal alveolar volume $\left(V_{A}\right)$ ( $x$-axis) compared to their percentage value at maximal $V_{A}$ (y-axis); and b) rates of alveolar uptake for $\mathrm{NO}$ and $\mathrm{CO}$ per unit time and pressure, KNo and KcO (mathematically equivalent to $D\left\llcorner N O / V_{A}\right.$ and $D\left\llcorner C O / V_{A}\right.$, respectively), and the membrane diffusing capacity $(D M)$ and pulmonary capillary volume $\left(V_{c}\right)$, both per unit alveolar volume $\left(V_{A}\right)\left(D_{M} / V_{A}\right.$ and $\left.V c / V_{A}\right)$, as the expansion of the lung is changed voluntarily in normal subjects $\left(100 \%\right.$ of maximal $V_{A}$, which is approximately total lung capacity, and $50 \%$ of maximal $V_{\mathrm{A}}$, which is approximately functional residual capacity). Note in a) that with diminishing lung expansion ( $\left.\triangle V_{A}\right), \Delta D\llcorner N O$ is better related to membrane diffusing capacity $(\triangle D M C O$ ) and $\triangle D M C O$ ) $V c$ change than the $D$ LCO change. In b), $\Delta K C O$ is a better reflection of changes in the pulmonary microcirculation (capillary volume per unit alveolar volume, $V_{\mathrm{C}} / V_{\mathrm{A}}$ ) than the $K_{\mathrm{NO}}$; decrease of $D \mathrm{M} / V_{\mathrm{A}}$ with $V_{\mathrm{A}}$ change suggests isotropic change as alveolar dimensions reduce with concomitant thickening of the alveolarcapillary membranes. Interrupted line (in b) signifies no change with change of $V_{A}$. Data from $[21,57]$.

volume. There are two ways in which the effect of heterogeneity on DLNO (and DLCO) has been assessed: first by modelling the distribution and uptake in a theoretical lung [51, 52]; and second by observing the effect of different breath-hold times on DLNO and DLCO in normal subjects and patients [53, 54].

Following the work of СоттоN et al. [55], Tsoukias et al. [52] demonstrated that the lungs fill sequentially, the first gas to be inspired being the last gas to be expired (first in, last out), and that the longer residence times for the first inspired gas would increase its alveolar NO uptake (this effect would be greater for NO because of its more rapid uptake than $\mathrm{CO}$ ). Thus, the later the expired gas portion was sampled, the higher the calculated DLNO. Note that the more familiar parallel model with slow and fast ventilated compartments, where the "slow" is "last in, last out" has identical functional implications. PIIPER and SIKAND [51] used the classical two-compartment parallel model in which DLCO and alveolar volume (the compartment or total lung volume $(V \mathrm{~A})$ ) during breath holding could be varied independently, and breath-hold time could also be altered. Note that DLNO is the product of VA during breath holding and KNO (rate of change of $\mathrm{NO}$ from alveolar gas, per unit pressure of $\mathrm{NO}$, and equivalent to $D \mathrm{LNO} / V_{\mathrm{A}}$ ). If KNO was uniform but alveolar volume was uneven between the two compartments, DLNO was less than if alveolar volume had been evenly distributed, but this underestimation was independent of breath-hold time [51]. If both KNO and alveolar volume were unevenly distributed, DLNO would be underestimated and this deficit would increase as breath-hold time was prolonged [51].

In the second approach, breath-hold time was varied for simultaneous DLNO and DLCO measurements in normal subjects and patients with airflow obstruction. DLNO and DLCO decrease as breath-hold time is prolonged [54] because the decrease in $\mathrm{KNO}$ (and $\mathrm{KCO}$ ) at a longer breath-hold time (more weight being given to the low KNO and KCO compartments) outweighs the increase in alveolar volume (more time for inert gas equilibration at $10 \mathrm{~s}$ breath-hold). DLNO and DLCO are affected similarly, so the effect of heterogeneity on the DLNO/DLCO ratio is small in normal subjects.

There is no recognised method that "corrects" the DLNO and DLCO for the effects of heterogeneity. Rather than analysing a "mixed", and possibly unrepresentative, "alveolar" sample, modern rapid gas analysers can measure concentrations in real time throughout expiration for $\mathrm{NO}, \mathrm{CO}$ and inert gases, so that the effects of dispersion (a sloping "alveolar plateau") can be recognised. Whether rapid gas analysers will permit a heterogeneity "correction" remains a subject for further research. What is already known is that heterogeneity of compartmental alveolar volume leads to underestimation of the overall VA measured at full inflation, in relation to a separately measured estimate of TLC [56]. In normal subjects who use the single-breath method and a $10 \mathrm{~s}$ breath-hold time, the mean \pm SD VA to TLC ratio is $0.94 \pm 0.07$ [56, 57], 
which is slightly less than 1.0, mostly due to sequential heterogeneity. Alveolar volumes from a single-breath test $<85 \%$ of the TLC (measured using a body plethysmograph) is associated with airflow obstruction [56]. One way of correcting for this mixing defect would be to calculate DLNO as KNOxTLC, where TLC is measured separately. Nonetheless, this has not found favour as it presumes that the KNO in the "inaccessible" units is the same as in the well-ventilated parts of the lung; which is unlikely to be the case for conditions such as emphysema.

In summary, heterogeneity becomes an issue when DLNO and DLCO at $10 \mathrm{~s}$ breath hold is compared to $5 \mathrm{~s}$ breath hold. There is a tendency for a trade-off between an increase in VA and a decrease in KNO and KCO (or vice versa) at $10 \mathrm{~s}$ versus $5 \mathrm{~s}$, so that dispersion of $V \mathrm{~A}$ and $D \mathrm{~L}$ affects each component of DLNO and DLCO in an opposite sense. The effects of heterogeneity are expected to be accentuated in abnormal lungs, although these effects have not undermined the clinical use of DLCO.

\section{Measurements of single-breath DLNO in normal subjects and in cardiopulmonary diseases}

By the late 1980s analysers could detect NO concentrations down to $1 \mathrm{ppb}$, allowing detection of back tension (endogenous respiratory tract production) of $\sim 10 \mathrm{ppb} \mathrm{NO}$ and longer breath-hold times, up to the conventional $10 \mathrm{~s}$. Now, rapidly responding analysers allow alveolar profile measurements by the intra-breath [50] and steady-state methods [58]. Commercial pulmonary function systems incorporating NO analysers also became available using a cheaper, but less sensitive NO electrochemical cell, requiring a shorter breath-hold time of 4-6 s. Studies appeared over the next 25 years measuring combined DLNO and DLCO in volunteers and in patients with different diseases.

\section{DLNO in the normal lung}

In normal subjects, DLNO decreases to a greater extent than DLCO when lung volume declines $[10,59]$ (figure 3). Compared to $100 \%$ of $V \mathrm{~A}, D \mathrm{LNO}$ is decreased by $40 \%$ when $V \mathrm{~A}$ is decreased by $~ 50 \%$ (figure 3 ). This is in opposition to DLCO, which only decreases by $\sim 25 \%$ for the same decrease in VA (figure 3 ). Thus, for the same decrease in lung volume, the percentage increase in KCO (DLCO/VA) is approximately double that of KNO $(D \mathrm{LNO} / V \mathrm{~A})$ (figure 3), reflecting greater DLNO dependence on the DMNO/VA ratio than on the $V \mathrm{C} / V \mathrm{~A}$ ratio.

After adjusting for postural changes in $V A$, both DLNO and DLCO increase $~ 5 \%$ from upright, sitting to supine [60], which may be explained by an $\sim 13 \%$ increase in $V C$ in the supine position compared to sitting [60]. In contrast, changing from a supine to a prone position has yielded varying results [61].

DLNO increases linearly with increasing exercise intensity, measured by the single-breath [19, 40, 41], steady-state [62] or rebreathing [35, 36, 42] methods (see figure $2 c$ for an example using rebreathing data).

After 2-30 days at altitude (4400-5000 m), DLNO and DLCO (at rest) increases in healthy lowlanders [18, 63, 64]. But acutely (2-3 days' exposure), the DLNO/DLCO ratio falls $(8 \%)$, and it returns towards baseline (along with DLNO and DLCO) after a week at altitude [63]. These increases in DLNO and DLCO on acute high altitude exposure may be explained by alveolar expansion (weighted by DLNO) and capillary recruitment (weighted by DLCO) due to hyperventilation and increased cardiac output.

In healthy high-altitude Quechuans in Peru [64], DLCO and DLNO are increased in relation to healthy lowlanders after 4 days at the same altitude, but the DLNO increase was smaller and the DLNO/DLCO ratio fell by $5 \%$. In a similar study involving Sherpas in Tibet, the relative increases in DLCO and DLNO were greater, but, again, there was a lower DLNO/DLCO ratio (by $\sim 12 \%$ ) [65]. In high-altitude Quechuans with chronic mountain sickness, DLCO and DLNO are increased further compared to healthy Quechuans, with a $\sim 8 \%$ decrease in the DLNO/DLCO ratio [64].

Diving has biphasic effects. Both DLCO and DLNO increase transiently after short compressed air or maximal breath-hold dives due to pulmonary vasodilation and central blood volume shifts that increase VC, followed later by parallel decreases in DLCO and DLNO reflecting the development of interstitial oedema and ventilation-perfusion mismatch [66-68]. Dives of longer durations are associated with reduced DLCO due to oxygen toxicity $[69,70]$.

\section{DLNO in disease}

When comparing DLNO in disease to a control group, it is helpful to examine DLNO and the simultaneously measured DLCO and the DLNO/DLCO ratio [21]. As DLNO is weighted by DM and DLCO is weighted by $V$ C, the DLNO/DLCO ratio (assuming DLNO and DLCO are reduced) reflects a relative change in the membrane-to-capillary components of uptake ( $\left.D \mathrm{MCO} / V_{C}\right)$ [21]. An increase in DLNO/DLCO signifies a reduction in $V \mathrm{C}$ greater than the reduction in $D \mathrm{M}$, meaning that there is greater microvascular disruption than membrane disruption (and vice versa for a decrease in DLNO/DLCO). Likewise, since DLNO is 
insensitive to changes in haematocrit in the physiological range, the DLNO/DLCO ratio should rise in anaemia and decrease in polycythaemia. As predicted, increasing $\mathrm{Hb}$ concentration by $33 \%$ (from 7.8 to $\left.10.4 \mathrm{~g} \cdot \mathrm{dL}^{-1}\right)$ by transfusion caused a minimal increase in DLNO $(\sim 3 \%, \mathrm{p}>0.05)$, while DLCO increased by $\sim 20 \%(\mathrm{p}<0.05)$, and the DLNO/DLCO ratio decreased from 5.7 to 4.8 [17].

\section{Microvascular disease}

In pulmonary arterial hypertension (PAH), studies [71-73] have shown a mainly microvascular component, with a reduction in $V \mathrm{C}$ greater than the reduction in DMCO, leading to a rise in $D \mathrm{MCO} / V_{\mathrm{C}}$ and DLNO/DLCO ratios. DMCO falls as VC falls because of their interdependence ("coupling"). Nevertheless, in patients with idiopathic $\mathrm{PAH}$, there were equal reductions in $D \mathrm{MCO}$ and $V \mathrm{C}$, but no change in the DLNO/ DLCO ratio [73]. In liver cirrhosis with hepatopulmonary syndrome (HPS) [74], there was a greater reduction in VC and DMCO (and a lower arterial oxygen pressure) versus non-HPS patients, but both groups demonstrated a similar rise in $D \mathrm{LNO} / D \mathrm{LCO}$ and $\mathrm{DMCO} / V \mathrm{C}$ ratios compared to controls, consistent with microvascular disease. In heart failure, DLNO/DLCO and DMCO/VC ratios were reported to be increased [75], contrary to predictions, but there were methodological issues in the calculations of $D \mathrm{MCO} / V \mathrm{C}$ [76]. As such, more studies are needed examining microvascular disease and its effects on diffusing capacity.

\section{Interstitial lung disease}

A greater reduction of $D$ MCO than $V C$ (with a fall in DLNO/DLCO ratio) was observed in patients with sarcoidosis using a rebreathing technique [35], whereas the opposite was found [72] using a single-breath technique in patients with diffuse parenchymal lung disease and PAH. The disparity could reflect the different pathophysiology and clinical stages of these diseases.

\section{Airflow obstruction}

In a lung cancer screening trial in asymptomatic smokers without airflow obstruction (Global Initiative for Chronic Obstructive Lung Disease stage 0) [77], DMCO was preserved in relation to VC, and the DLNO/ $D \mathrm{LCO}$ and $\mathrm{DMCO} / \mathrm{VC}$ ratios were increased compared to controls (Borland and Hughes, personal communication), suggesting that a reduction in $V C$ may be an early sign of chronic obstructive pulmonary disease (COPD). In established COPD, both DM and VC appear to be reduced [53].

\section{Miscellaneous}

In chronic renal failure [78], DLNO and both $D \mathrm{MCO} / V_{\mathrm{C}}$ and $D \mathrm{LNO} / D \mathrm{LCO}$ ratios are reduced (after adjusting for $\mathrm{Hb}$ ). In morbid obesity $[40,79]$ there is a slight reduction in $D \mathrm{MCO} / V \mathrm{C}$. In cystic fibrosis $D \mathrm{MCO} / V_{\mathrm{C}}$ and DLNO/DLCO are reduced [80]. Following bone marrow transplant, both DLNO and DLCO are reduced [81].

\section{Conclusion}

Different pathologies will reduce the membrane $(D M)$ and microvascular $(\theta \cdot V C)$ components differently and, within a specific disease, affected and less- or non-affected areas may co-exist. Thus, heterogeneity of function within and between pathological entities means that disease-specific patterns of DLNO and DLCO, DLNO/DLCO, DMCO and VC will remain imprecise until more clinical studies are reported using a standardised technique.

\section{Gas analysers and general equipment} System design

All commercially available DLNO apparatus is based on the single-breath DLCO measurement system with the addition of the NO transfer gas. The first requirement is that the inspiratory gas sample is prepared, mixed and stored for the subsequent inhalation. Because both inspiratory and expiratory gas concentrations have to be measured, gas analysers have to be connected with the inspiratory reservoir and the expiratory sampling bag. Increasingly, continuous high-speed gas analysers are used and recommended. With electrochemical (low sensitivity, low speed) analysers, the inspired gases should be sampled from the inspiratory reservoir. As such, in relation to the patient's mouth, the gas sampling port should be near the inspiratory-expiratory switching valve; for the combined one-step NO-CO manoeuvre, sampling of the inspired $\mathrm{NO}, \mathrm{CO}$, inert tracer gas and oxygen concentrations should be from the inspiratory reservoir itself. On expiration, continuous gas analysis defines the extent of the anatomical dead space, and allows different parts of the subsequent "alveolar plateau" to be examined. High-speed gas analysis, with continuous sampling, is required if the three-equation model (inhalation, breath holding and exhalation) of diffusing capacity is applied [82]. Finally, the inspired and expired volume must be measured using pneumotachometers or mass flow meters [83].

\section{Performance standards for equipment}

The standard DLNO system is basically a single-breath DLCO system with the addition of NO in the inspiratory gas mixture and the presence of an NO analyser. Two major subtypes can be defined: the first 
type is characterised by an inspiratory reservoir, such as a balloon, for the storing and measurement of the inspiratory gas mixture. The second type has a mixing chamber in which the inspired gases are mixed, from different sources, before each inspiration. The basic equipment for DLCO systems has been described elsewhere [84]. Importantly, $\mathrm{NO}$ is reactive with oxygen $\left(\mathrm{O}_{2}\right)$, to form $\mathrm{NO}_{2}\left(\mathrm{O}_{2}+2 \cdot \mathrm{NO} \rightarrow 2 \cdot \mathrm{NO}_{2}\right) \cdot \mathrm{NO}_{2}$ is formed at a rate of $\sim 0.02 \mathrm{ppm} \cdot \mathrm{s}^{-1}\left(\sim 1.2 \mathrm{ppm} \mathrm{NO} \mathrm{NO}_{2} \cdot \mathrm{min}^{-1}\right)$ in a gas mixture containing close to $21 \%$ oxygen and 60 ppm $\mathrm{NO}$ [85]; $<3$ ppm of $\mathrm{NO}_{2}$ is produced in 2 min when $\sim 60 \mathrm{ppm}$ NO gas is mixed with $\sim 21 \%$ oxygen [85]. Were that mixture to be left in the inspiratory bag for 2 min before testing, DLNO would be overestimated by $\sim 1 \%$. As such, $\mathrm{NO}$ gas (along with nitrogen $\left(\mathrm{N}_{2}\right)$ ) is stored in a separate gas cylinder (apart from oxygen) containing $\mathrm{NO}$ in a high concentration in $\mathrm{N}_{2}$, ranging from 400 to $1200 \mathrm{ppm} \mathrm{NO}$ in $\mathrm{N}_{2}$. The greater the concentration of $\mathrm{NO}$ with $\mathrm{N}_{2}$ in the cylinder, the less $\mathrm{N}_{2}$ is injected into the inspiratory bag, with less dilution of the inspired oxygen concentration. Since NO reacts with certain plastics, polytetrafluoroethylene (Teflon) tubing should be used. The connections and regulators should be made of stainless steel in order to prevent reaction of the NO with metals. Two types of NO analysers are available: the highly sensitive but expensive chemiluminescence analysers, with a lower detection limit of $0.5 \mathrm{ppb}$, and linear to the upper detection limit of $500 \mathrm{ppm}$ and with a reaction time of $\sim 70 \mathrm{~ms}$. Because the chemiluminescence analysers are expensive, commercial pulmonary function testing equipment that performs DLNO measurements is usually equipped with a less expensive, slower speed, less sensitive, NO electrochemical cell. These cells have lower sensitivity, with a detection range of 0-100 ppm, and a response time of $<10 \mathrm{~s}$ ( $90 \%$ full scale), and so are suitable only for the standard single-breath test.

Typically, in the single-breath DLCO, a breath-hold time is $10 \pm 2 \mathrm{~s}$ calculated by the Jones and MEADE formula [86]. If an electrochemical cell is used for the DLNO test, a shorter breath-hold time of $4-6 \mathrm{~s}$ is necessary because of the lower sensitivity of the analyser. For this purpose, prediction equations for DLNO, DLCO, DMCO and VC have been developed by combining several studies using breath-hold times that varied between $4 \mathrm{~s}$ and $10 \mathrm{~s}$ (with a mean of $\sim 6 \mathrm{~s}$ ). Subject characteristics are presented in table 1 and prediction equations are presented in table 2. Supplementary appendix $\mathrm{H}$ allows patients' individual values to be inserted in relation to predicted values.

Nevertheless, there is a disadvantage of using shorter breath-hold times of $5 \mathrm{~s}$ instead of $10 \mathrm{~s}$ for combined DLNO and DLCO measurement. In adult subjects with ventilatory heterogeneity, the shorter breath-hold times can overestimate the diffusion capacity $[54,82]$ versus the conventional $10 \mathrm{~s}$ test. However, in healthy children the difference between $10 \mathrm{~s}$ and $5 \mathrm{~s}$ breath-hold times is small [87].

Inspiratory NO concentrations of 40-60 ppm should be used, leading to expiratory NO levels that are $\sim 3-5$ ppm after a $\sim 5$ s breath hold $[49,88]$. Even after 22 consecutive DLNO tests on subjects that inspired $\sim 55 \mathrm{ppm}$ NO for each test, DLNO remained unchanged [48]. Furthermore, there is minimal interaction between NO and CO $[10,50]$, therefore the DLNO and DLCO can be measured simultaneously. The

TABLE 1 Subject characteristics from previously published studies from which prediction equations were made [57, 106, 107]

\begin{tabular}{|c|c|c|c|}
\hline & Males & Females & Combined \\
\hline Subjects & 248 & 242 & 490 \\
\hline Age years & $44 \pm 17(18-93)$ & $45 \pm 18(18-87)$ & $44 \pm 17(18-93)$ \\
\hline Weight kg & $76.7 \pm 9.4(55.0-105.0)$ & $61.6 \pm 8.8(44.0-95.0)$ & $69.3 \pm 11.8(44.0-105.0)$ \\
\hline Height $\mathrm{cm}$ & $176 \pm 8(154-196)$ & $164 \pm 7(147-182)$ & $170 \pm 10(147-196)$ \\
\hline Body mass index $\mathrm{kg} \cdot \mathrm{m}^{-2}$ & $24.7 \pm 2.5(18.9-29.9)$ & $23.0 \pm 3.0(17.2-29.8)$ & $23.8 \pm 2.9(17.2-29.9)$ \\
\hline DLNO $\mathrm{mL} \cdot \mathrm{min}^{-1} \cdot \mathrm{mmHg}^{-1}$ & $164 \pm 31(67-235)$ & $119 \pm 25(47-186)$ & $142 \pm 36(47-235)$ \\
\hline DLco $\mathrm{mL} \cdot \mathrm{min}^{-1} \cdot \mathrm{mmHg}^{-1}$ & $34.1 \pm 6.3(11.9-49.9)$ & $25.1 \pm 5.3(11.3-38.6)$ & $29.6 \pm 7.4(11.3-49.9)$ \\
\hline DMco $\mathrm{mL} \cdot \mathrm{min}^{-1} \cdot \mathrm{mmHg}^{-1}$ & $161 \pm 39(72-250)$ & $104 \pm 26(33-182)$ & $133 \pm 44(33-250)$ \\
\hline$V c \mathrm{~mL}$ & $78 \pm 16(25-121)$ & $65 \pm 15(30-105)$ & $72 \pm 17(25-121)$ \\
\hline$D_{M C O} /$ Vc ratio $\min ^{-1} \cdot \mathrm{mmHg}^{-1}$ & $2.11 \pm 0.57(1.01-4.03)$ & $1.63 \pm 0.40(0.88-2.96)$ & $1.90 \pm 0.57(0.88-4.03)$ \\
\hline $\mathrm{Kco} \mathrm{mL} \cdot \mathrm{min}^{-1} \cdot \mathrm{mmHg}^{-1} \cdot \mathrm{L}^{-1}$ & $4.9 \pm 0.8(2.7-7.1)$ & $4.8 \pm 0.7(3.0-6.8)$ & $4.9 \pm 0.8(2.7-7.1)$ \\
\hline KNo $\mathrm{mL} \cdot \mathrm{min}^{-1} \cdot \mathrm{mmHg}^{-1} \cdot \mathrm{L}^{-1}$ & $23.8 \pm 3.9(13.7-34.2)$ & $22.8 \pm 3.2(13.5-31.5)$ & $23.3 \pm 3.6(13.5-34.2)$ \\
\hline DLno/Dıco ratio & $4.83 \pm 0.40(3.83-5.82)$ & $4.74 \pm 0.39(3.85-5.78)$ & $4.79 \pm 0.40(3.83-5.82)$ \\
\hline
\end{tabular}

Data are presented as $\mathrm{n}$ or mean \pm SD (range). The alveolar-capillary membrane diffusing capacity for carbon monoxide (DMCO) and total volume of blood in the lung capillaries exposed to alveolar air $(\mathrm{VC})$ values reported in these studies $[57,106,107]$ have been recalculated according to the parameters listed in table 4. DLNO: diffusing capacity of the lung for nitric oxide; DLCO: diffusing capacity of the lung for carbon monoxide; Kco: rate of uptake of carbon monoxide from alveolar gas; KNO: rate of uptake of nitric oxide from alveolar gas. 
TABLE 2 Predictive equations for white adults at a breath-hold time of $\sim 6 \mathrm{~s}$, inspired nitric oxide (NO) of $\sim 35 \mathrm{ppm}$ and inspired oxygen of $\sim 19.5 \%$, from three studies $[57,106,107]$

\begin{tabular}{|c|c|c|c|c|c|c|c|}
\hline & Height $\mathrm{cm}$ & $\mathrm{Age}^{2}$ & Sex & Constant & Adjusted $\mathrm{R}^{2}$ & SEE & LLN and ULN \\
\hline DLco $\mathrm{mL} \cdot \mathrm{min}^{-1} \cdot \mathrm{mmHg}^{-1}$ & 0.23 & -0.002 & 6.0 & -8.5 & 0.68 & 4.2 & \pm 8.2 \\
\hline DLNO $\mathrm{mL} \cdot \mathrm{min}^{-1} \cdot \mathrm{mmHg}^{-1}$ & 0.81 & -0.010 & 34.4 & 9.7 & 0.69 & 20.0 & \pm 39.2 \\
\hline Dмсо $\mathrm{mL} \cdot \mathrm{min}^{-1} \cdot \mathrm{mmHg}^{-1}$ & & -0.011 & 56.4 & 129.6 & 0.61 & 27.3 & \pm 53.5 \\
\hline$V c \mathrm{~mL}$ & 0.84 & -0.004 & & -59.9 & 0.49 & 12.0 & \pm 23.5 \\
\hline$V A \mathrm{~L}$ & 0.079 & & 0.73 & -7.7 & 0.67 & 0.72 & \pm 1.4 \\
\hline$V c / V_{A} \mathrm{~mL} \cdot \mathrm{L}^{-1}$ & & -0.0006 & -1.25 & 13.9 & 0.27 & 1.89 & \pm 3.70 \\
\hline$D_{M c o} / V_{A} \mathrm{~mL} \cdot \min ^{-1} \cdot \mathrm{mmHg}^{-1} \cdot \mathrm{L}^{-1}$ & -0.200 & -0.002 & 5.9 & 56.6 & 0.41 & 3.81 & \pm 7.47 \\
\hline$K \operatorname{co~} \mathrm{mL} \cdot \mathrm{min}^{-1} \cdot \mathrm{mmHg}^{-1} \cdot \mathrm{L}^{-1}$ & & -0.00027 & & 5.5 & 0.34 & 0.6 & \pm 1.2 \\
\hline KNo $\mathrm{mL} \cdot \mathrm{min}^{-1} \cdot \mathrm{mmHg}^{-1} \cdot \mathrm{L}^{-1}$ & & -0.00137 & & 26.4 & 0.39 & 2.8 & \pm 5.5 \\
\hline
\end{tabular}

Alveolar-capillary membrane diffusing capacity for carbon monoxide (DMco) and total volume of blood in the lung capillaries exposed to alveolar air $(V c)$ values in these studies [57, 106, 107] have been recalculated according to the formulas and constants in table 4 and then re-analysed for the regression. A predictive model was not found for the ratio of diffusing capacities of the lung for nitric oxide and carbon monoxide ( $D\llcorner\mathrm{NO} / D\llcorner\mathrm{LO})$. Sex: 1 for male, 0 for female; SEE: standard error of the estimate. To convert $D\llcorner\mathrm{NO}, D\llcorner C O$ and DMCO to $\mathrm{mmol} \cdot \mathrm{min}^{-1} \cdot \mathrm{kPa}^{-1}$, divide by 3. Lower limit of normal (LLN)=2.5th percentile; upper limit of normal (ULN)=97.5th percentile. $n=490$. $V_{A}$ : alveolar lung volume; $K \mathrm{CO}$ : rate of uptake of carbon monoxide from alveolar gas; KNO: rate of uptake of nitric oxide from alveolar gas. Supplementary appendix H allows the patient's individual values to be inserted in relation to the predicted values.

preferred inspired test gas concentrations for DLCO measurement are close to $0.30 \%$ CO and $21 \% \mathrm{O}_{2}$ [84]. For measurement of $\mathrm{VA}$, either $10 \% \mathrm{He}$ or $0.3 \% \mathrm{CH}_{4}$ can be used.

Linearity and accuracy

Since DLCO and DLNO are very sensitive to errors in relative gas concentration, nonlinearity for CO, NO and tracer gas analysers should not exceed $1.0 \%$ of full scale for discrete systems. That is, any nonlinearity must not exceed $1.0 \%$ of full scale once zero and full-scale values have been set [84]. The CO, NO and tracer gas analysers should be accurate to within $1.0 \%$ of full scale [84].

Drift

The gas analysers should have minimal drift in zero and gain so that the output is stable over the test interval. Drift is determined by comparing the CO, NO and tracer values measured in room air immediately prior to and immediately following the single-breath manoeuvre. The $\mathrm{CO}$ analyser drift should be $\leqslant 10 \mathrm{ppm}$ (or $\leqslant 0.33 \%$ drift) when inhaling $3000 \mathrm{ppm} \mathrm{CO}, \leqslant 1 \mathrm{ppm}$ when inhaling $40-60 \mathrm{ppm} \mathrm{NO}$ and $\leqslant 0.5 \%$ for the tracer gas over $30 \mathrm{~s}$. It would be preferable to have a display of the measured gas concentrations so that stability is confirmed. If significant drift is present over the 30 -s time period (i.e. $>10 \mathrm{ppm} \mathrm{CO},>1 \mathrm{ppm} \mathrm{NO}$ (since the resolution of a typical NO electrochemical cell is $0.5-1 \mathrm{ppm}$ ) and $>0.5 \%$ for tracer gas), then adjustment algorithms should be devised to compensate for the analyser drift from measured data.

\section{Interference and noise}

Carbon dioxide and water can interfere with the gas analyser performance, for which corrections should be made [84] (refer to supplementary appendix D). Circuit resistance should be $<1.5 \mathrm{cmH}_{2} \mathrm{O} \cdot \mathrm{L}^{-1} \cdot \mathrm{s}^{-1}$ at $6 \mathrm{~L} \cdot \mathrm{s}^{-1}$ flow [84]. Anatomical dead space volume should be measured; the dead space volume of valve, filter and mouthpiece should be $<200 \mathrm{~mL}$ [84]. The system, including all tubing, should be leak free.

\section{Flow and volume}

Flow measurement accuracy over a range of $\pm 10 \mathrm{~L} \cdot \mathrm{s}^{-1}$ must be within $2 \%$ [84]. For calibration with a 3-L syringe, a $2.5 \%$ volume accuracy $( \pm 75 \mathrm{~mL})$, including $0.5 \%$ for testing syringe error, is recommended [84].

\section{Equipment quality control}

Research shows that $36-70 \%$ of the variation in DLCO can be due to instrument choice [89]. We assume that the same variation exists for DLNO. Therefore, calibration and standardisation of equipment specifications are necessary [90].

1) Gas analysers should be zeroed before each test, and the zero level should be measured after each test, preferably via an automated procedure. If there is a difference between the zero level before and after each test, adjustment algorithms should be devised to compensate for the analyser drift from 
measured data. If using a discrete system, the inspired NO concentration should be checked after its injection into inspiratory reservoir, just prior to testing.

2) Volume calibration should be performed on a daily basis with the aid of a validated 3-L syringe.

3) Once a week or whenever problems are suspected, leak testing on the syringe should be performed. This is achieved by filling the 3-L syringe fully with air and then placing a stopper at the syringe input. Push the syringe in by $50 \mathrm{~mL}$ and hold for $10 \mathrm{~s}$ and release. If the syringe does not return to within $10 \mathrm{~mL}$ of the full position, it should be sent for repair. The procedure is then repeated with the syringe at $50 \mathrm{~mL}$ below full, applying the stopper and pulling the syringe to the full position [84].

4) Every week, standard subject testing (biological control) should be performed on healthy nonsmokers. Attention should be paid whenever the DLCO varies by $\geqslant 5.0 \mathrm{~mL} \cdot \mathrm{min}^{-1} \cdot \mathrm{mmHg}^{-1}$ or DLNO varies by $\geqslant 20 \mathrm{~mL} \cdot \mathrm{min}^{-1} \cdot \mathrm{mmHg}^{-1}$, from the mean of previously obtained values (table 3 ). A biological control whose DLNO and DLCO values measured week to week on the same pulmonary function system should be within 20 and $5 \mathrm{~mL} \cdot \mathrm{min}^{-1} \cdot \mathrm{mmHg}^{-1}$, respectively, $95 \%$ of the time. If there are week-to-week changes in diffusing capacity beyond those limits, then this would indicate that there is only a $5 \%$ chance that the diffusing capacity value obtained in the present week is not a real change and is due to machine error or some other factor. The DLNO and DLCO should be recorded in a laboratory log book so that slowly drifting values are noticed. Standard subject testing should be performed every time gas cylinders are changed.

5) Linearity of gas analysers should be tested every month, for $\mathrm{He} / \mathrm{CH}_{4}, \mathrm{CO}$ and $\mathrm{NO}$, by using serial dilutions of known test gas concentrations. Most importantly, laboratory staff should review the DLCO and DLNO, inspiratory vital capacity and VA values in every test, not only to observe the week-to-week variability (table 3), but also to identify aberrations of the expected values due to technical matters.

Using a 3-L syringe at ambient temperature and pressure (ATP), linearity issues may also be identified by performing the following test: with $\sim 1 \mathrm{~L}$ of air in the syringe, the remaining $2 \mathrm{~L}$ is filled with the test gases. The syringe is then emptied following the $4-6 \mathrm{~s}$ breath hold. The calculation of VA must be within

TABLE 3 Intra-session and inter-session variability of single-breath measurements of the diffusing capacities of the lung for nitric oxide ( $D\llcorner N O)$ and carbon monoxide ( $D\llcorner C O)$ ( $5 \mathrm{~s}$ breath hold) at rest

$\begin{array}{ccc}\begin{array}{c}\text { Test-to-test measurement } \\ \text { error (within the same }\end{array} & \begin{array}{c}\text { Repeatability } \\ \text { (within the same }\end{array} & \begin{array}{c}\text { Reproducibility } \\ \text { (w) } \\ \text { (week-to-week or }\end{array} \\ & \text { testing session) } & \begin{array}{c}\text { month-to-month change) } \\ \text { More stringent }\end{array}\end{array}$

Smallest measurable
change ${ }^{+}$(week-to-week or
month-to-month change)
Less stringent

\begin{tabular}{|c|c|c|c|c|}
\hline \multicolumn{5}{|l|}{ DLno } \\
\hline $\mathrm{mL} \cdot \mathrm{min}^{-1} \cdot \mathrm{mmHg}^{-1}$ & $6.2(4)$ & $17(10)$ & $20(13)$ & $10(7)$ \\
\hline $\mathrm{mmol} \cdot \mathrm{min}^{-1} \cdot \mathrm{kPa}^{-1}$ & $2.1(4)$ & $5.8(10)$ & $6.5(13)$ & $3.3(7)$ \\
\hline \multicolumn{5}{|l|}{ DLco } \\
\hline $\mathrm{mL} \cdot \mathrm{min}^{-1} \cdot \mathrm{mmHg}^{-1}$ & $1.2(4)$ & $3.2(10)$ & $4.9(16)$ & $2.5(8)$ \\
\hline $\mathrm{mmol} \cdot \mathrm{min}^{-1} \cdot \mathrm{kPa}^{-1}$ & $0.4(4)$ & $1.1(10)$ & $1.6(16)$ & $0.8(8)$ \\
\hline DLNo/DLco ratio & $0.12(2)$ & $0.36(7)$ & $0.23(5)$ & 0.13 (3) \\
\hline \multicolumn{5}{|l|}{ DMco } \\
\hline $\mathrm{mL} \cdot \mathrm{min}^{-1} \cdot \mathrm{mmHg}^{-1}$ & 12 (7) & 34 (19) & $47(28)$ & 24 (28) \\
\hline $\mathrm{mmol} \cdot \mathrm{min}^{-1} \cdot \mathrm{kPa}^{-1}$ & $4.1(7)$ & $11.2(19)$ & $15.8(28)$ & $8(14)$ \\
\hline$V c \mathrm{~mL}$ & $4(5)$ & 10 (13) & $16(24)$ & $8(12)$ \\
\hline \multicolumn{5}{|c|}{ 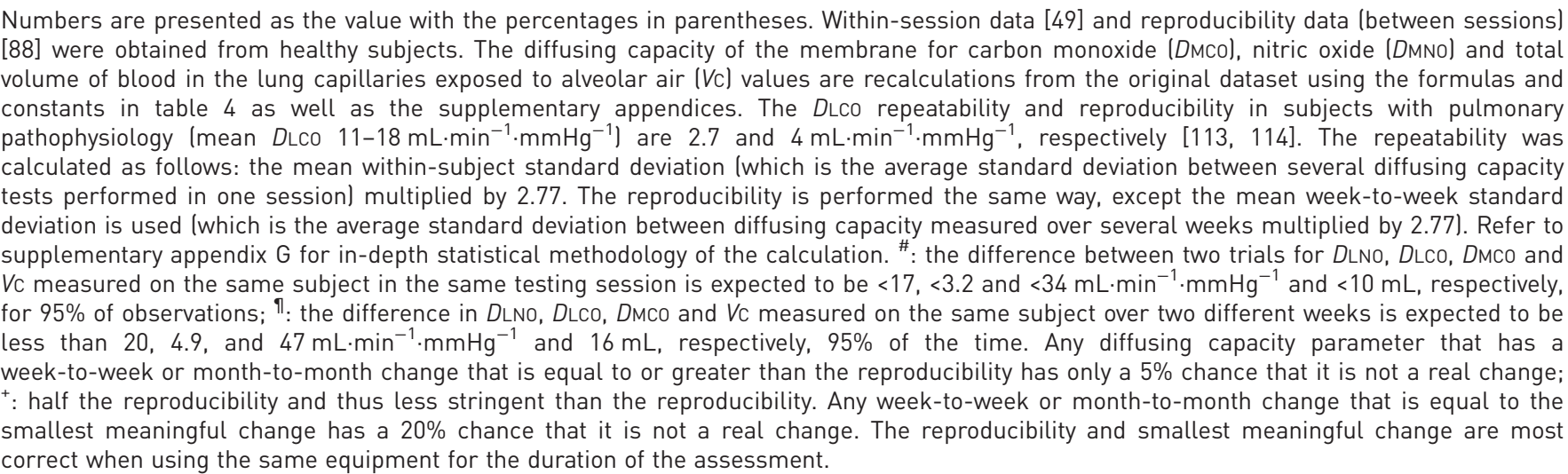 } \\
\hline
\end{tabular}


$0.3 \mathrm{~L}$ of $3 \mathrm{~L}$ with the syringe dead space being used for the anatomical dead space in the VA calculation. The absolute value for DLCO must be $<0.5 \mathrm{~mL} \cdot \mathrm{min}^{-1} \cdot \mathrm{mmHg}^{-1}\left(<0.167 \mathrm{mmoL} \cdot \mathrm{min}^{-1} \cdot \mathrm{kPa}^{-1}\right)$ and for DLNO $<3 \mathrm{~mL} \cdot \mathrm{min}^{-1} \cdot \mathrm{mmHg}^{-1}\left(<1 \mathrm{mmoL} \cdot \mathrm{min}^{-1} \cdot \mathrm{kPa}^{-1}\right)$. Manufacturers should provide this test option, which is the same as the usual testing procedure for a patient, with the exception that VA will be reported at ATP rather than body temperature, ambient pressure, saturated with water vapour (BTPS) [84].

Infection

Transmission of infection from patients to other patients or staff must be prevented. The spirometry guidelines also apply to DLCO and DLNO, as is described in detail elsewhere [91].

\section{Testing technique}

Subject preparation

Since a DLCO measurement is often performed in conjunction with a DLNO test, the carboxyhaemoglobin $(\mathrm{COHb})$ concentration should be minimised, as $\mathrm{COHb}$ reduces DLCO. Since it takes up to $6 \mathrm{~h}$ to remove half the CO from blood at rest breathing room air [92], subjects should refrain from smoking for $12 \mathrm{~h}$ prior to testing, and any deviation should be indicated in the report. As urban pollution can also increase $\mathrm{COHb}$ levels, where possible the $\mathrm{COHb}$ or an exhaled breath sample should be measured so that the predicted DLCO can be adjusted.

Subjects should refrain from wearing clothing that substantially restricts full chest and abdominal expansion, and from eating a large meal within $2 \mathrm{~h}$ of testing. Also, evidence indicates that DLNO [93, 94] and DLCO $[93,95,96]$ remain impaired for several hours after strenuous exercise. Thus, while DLNO and DLCO increase during exercise, and the increase parallels exercise intensity (i.e. cardiac output), both DLNO and DLCO are reduced 1-2 h post-exercise [93-96], and can last several hours post-exercise [95, 96]. The mechanisms for this reduction could be a combination of several factors: alveolar-membrane thickening due to mild interstitial pulmonary oedema $[93,94,97]$ or reduced pulmonary capillary blood volume due to active pulmonary vasoconstriction and/or peripheral vasodilation [95, 96]. As such, diffusing capacity testing should be avoided $\leqslant 12 \mathrm{~h}$ after vigorous exercise.

The subject's demographic information, body position, $\mathrm{Hb}$ concentration and the ambient room temperature and atmospheric pressure should be recorded. Any special conditions, e.g. exercise or altered inspired $\mathrm{O}_{2}$ fraction, or medication that affects lung function or vasomotor tone, e.g. bronchodilators or $\beta$-blockers, should be noted. Baseline lung function parameters measured by spirometry should be obtained. Subjects should be comfortably seated. Prior to testing, each subject should be familiarised with the testing equipment and instructed on the breathing manoeuvres, first via demonstration then by asking the subjects to perform practice manoeuvres with the mouthpiece and nose clip in place.

\section{Performing the manoeuvre}

In both clinical and laboratory practice, should the DLNO be performed simultaneously with DLCO, the current DLCO guidelines should be followed [84]. Following a period of quiet tidal breathing to stabilise respiratory pattern, the single-breath technique for DLNO-DLCO involves rapid inspiration from residual volume to total lung capacity of a bolus of a test gas mixture containing a known quantity of NO (usually with $\mathrm{CO}$ and an inert tracer gas such as $\mathrm{He}, \mathrm{CH}_{4}$ or neon); achieving an inspired volume of at $\geqslant 90 \%$ of inspiratory vital capacity in $<2.5 \mathrm{~s}$ is preferred. At full inspiration, the subject will hold the breath for a prescribed period $(5-10 \mathrm{~s})$ at near atmospheric intrapulmonary pressure. A subject that relaxes on the shutter during apnoea (in effect, increasing intrathoracic pressure) will decrease DLCO by $\sim 3 \%$ $\left(1 \mathrm{~mL} \cdot \mathrm{min}^{-1} \cdot \mathrm{mmHg}^{-1}\right)$ [98]. As such, subjects should refrain from making Valsalva (forced positive pressure against a closed glottis) and Müller manoeuvres (increased negative pressure in the thorax), because these will alter thoracic and pulmonary capillary blood volume. Following breath hold, the subject exhales smoothly and rapidly to residual volume within $4 \mathrm{~s}$. The actual duration of exhalation should be measured and recorded. If continuous monitoring of expired gas concentrations is available, the washout of tracer gas from the previous test may be confirmed by observing end-tidal gas concentrations before beginning the next test. Secondly, if continuous monitoring of expired gas concentrations is available, the timing of the alveolar gas sample should be determined as the point of dead space washout rather than using a fixed washout volume of $0.75-1 \mathrm{~L}[84,99]$.

Between successive tests, an interval of $\geqslant 4-5$ min should be allowed to ensure complete elimination of prior test gases from the lungs. A longer interval between tests may be necessary in subjects with poor gas mixing due to intrapulmonary airflow obstruction. For systems using continuous monitoring, verification of washout rather than using an arbitrary 4-5-min washout interval is preferable. Should the tests be repeated on separate days, they should be performed around the same time of the day to minimise potential variability in the DLCO due to diurnal fluctuations in Hb and COHb [100, 101]. The DLCO 
decreases by $0.4 \%$ [101] to $1.2 \%$ [100] per hour from $09: 30 \mathrm{~h}$ to $17: 30 \mathrm{~h}$. There is no reason to suggest that DLNO alters throughout the day, since small changes in $\mathrm{Hb}$ and $\mathrm{COHb}$ do not affect it $[17,48]$.

\section{Sample collection}

The initial volume of gas expired from the anatomical dead space is routinely discarded before collecting the alveolar gas sample. This "washout volume" may be arbitrarily set (0.75-1.0 L at BTPS for most adults, or $0.50 \mathrm{~L}$ BTPS for subjects with a small vital capacity $<2.0 \mathrm{~L}$ ), or individually determined in cases where exhaled gas concentrations are monitored continuously throughout expiration with rapid gas analysers.

Following dead space washout, which includes instrument, mouthpiece, valve, filter and anatomical and physiological dead spaces, an alveolar sample of $0.5-1.0 \mathrm{~L}$ is collected for analysis. In subjects with small vital capacities, a dead space washout volume $<0.5 \mathrm{~L}$ may be acceptable as long as all the dead spaces have been cleared. The actual parameters used in sample collection and any customised adjustments should be reported.

In subjects with poor gas mixing or marked sequential emptying of various lung regions, the gas sample collected will only reflect the properties of the regions contributing to that sample.

\section{Inspired gases}

The test gases used to calculate DLCO, include CO (usually close to $0.3 \%$ ) and a tracer gas such as $\mathrm{He}$ (usually $\sim 10 \%$ ), $\mathrm{CH}_{4}$ or neon (both usually $\sim 0.3 \%$ ) for measuring $V \mathrm{~A}$. The remainder of the test gas mixture includes close to $21 \%$ oxygen with nitrogen as balance so that the average alveolar oxygen pressure of $\sim 100 \mathrm{mmHg}$ is reached during a maximal inspiration to total lung capacity with a 6-s breath-hold. As the DLCO increases by $\sim 1.5 \%$ for every $1 \%$ decrease in inspired oxygen concentration $[16,102,103]$, the DLNO/DLCO ratio should decrease by $\sim 3 \%$ when the inspired oxygen concentration is lowered from $21 \%$ to $19 \%$ (due to the increase in DLCO only). In fact, studies show that for every $1 \%$ decrease in inspired oxygen concentration, the measured DLNO/DLCO ratio decreases by $\sim 2 \%[16,102]$. It is important to note that while the traditional diffusion gas mixtures report $21 \%$ oxygen in their gas tanks, by the time it reaches the inspiratory bag and gets slightly diluted with the $\mathrm{NO} / \mathrm{N}_{2}$ mixture, the inspired oxygen concentration may be closer to $20 \%$ (supplementary appendix F).

If $D M C O$ and $V C$ are to be calculated from the one-step NO-CO technique (supplementary appendix E), the expired "alveolar" oxygen concentration should be measured so that $\theta \mathrm{CO}$ can be calculated. The oxygen concentration in the expired sample is a good approximation of the alveolar oxygen pressure. If the expired sampled oxygen concentration is $15 \%$ then the estimated alveolar oxygen pressure at sea level would be the current atmospheric pressure minus the water vapour pressure $\left(\sim 47 \mathrm{mmHg}\right.$ at $\left.37^{\circ} \mathrm{C}\right)$ multiplied by $0.15=107 \mathrm{mmHg}$. In a $5 \mathrm{~s}$ breath-hold test in normal subjects where the mean inspired oxygen concentration was $19-20 \%$, the mean expired oxygen concentration sampled from the expiratory reservoir ranged from $15 \%$ to $17 \%[49,88]$.

The gases in the inspiratory reservoir are at ambient temperature and pressure, dry conditions (ATPD). The inspired volume (the subject's inspired vital capacity), and the VA calculated from it needs to be converted from ATPD to BTPS conditions for calculation of DLNO/VA (equivalent to KNO), and standard temperature and pressure, dry $\left(760 \mathrm{mmHg}, 0^{\circ} \mathrm{C}, 0 \%\right.$ humidity) conditions for the calculation of DLNO (equals $K \mathrm{NO} \times V \mathrm{~A})$. Manufacturers should specify these conversion factors in the software.

\section{Calculations for DLNO, DLCO and VA}

The derivation and calculation of DLNO and DLCO are identical except for the difference in gas species. The formulation (supplementary appendix B) given for DLNO stems from a recent review [104] and emphasises an important concept, that the DLNO (and DLCO) are each the product of two components, the rate of change of alveolar concentration $(k \mathrm{NO}$ and $k \mathrm{CO})$ per unit total gas pressure $\left(P \mathrm{~B}-\mathrm{P}_{\mathrm{H}} \mathrm{O}\right)$ and the volume of distribution of that gas in the alveolar region of the lung (VA). This concept derives from Marie Krogh, who was the originator of the DLCO measurement in 1915 [105]. It is important that the total dead space (anatomical dead space and the instrumental dead space) are taken into consideration in the calculation of $V \mathrm{~A}$, otherwise errors in the calculation of alveolar volume will occur (supplementary appendix C).

\section{Calculating breath-hold time}

Subjects are encouraged, from the start, to breathe in "as rapidly as possible", from residual volume to TLC, otherwise known as an inspiratory vital capacity. At TLC, the usual breath-hold time is $\sim 4-10 \mathrm{~s}$ for DLNO measurements. The shorter breath-hold time is permitted if NO is measured using the less sensitive electrochemical cell. At the end of the breath hold, the expiration for the collection of an alveolar sample need not be "forced", as the combined recoil of the chest wall and the lung ensures that it will be "rapid" (unless there is severe, usually extrathoracic airflow obstruction). 
Ideally, in the single-breath test, all contact of $\mathrm{NO}$ and $\mathrm{CO}$ with the alveolar surface should be at a breath-hold volume close to TLC. Since neither the preceding inspiration nor the subsequent expiration is "instantaneous", that ideal cannot be fulfilled. Jones and Meade [86] addressed the problem of an "effective breath-hold time" in some depth, and their recommendations for its calculation have been accepted [99]. Breath-hold time starts after the first 30\% of inspiratory time and finishes halfway through the collection of the expired sample (after an initial expiration of 750-1000 mL). Thus, this task force agrees that the Jones-Meade formula be used.

Use of breath-hold times $<10 \mathrm{~s}$

Because the alveolar uptake of $\mathrm{NO}$ is five times faster than the uptake of CO (figure 2a), alveolar NO concentration is $\sim 5 \%$ of the inspired concentration after $5 \mathrm{~s}$ of breath holding, and $\sim 1 \%$ after $10 \mathrm{~s}$. To maximise the expired NO signal, investigators in epidemiological studies have reduced breath-hold times to $4 \mathrm{~s}$ [106] or $5.5 \mathrm{~s}$ [107], although others, with more sensitive analysers, have kept to $10 \mathrm{~s}$ [57].

Implications for breath-hold times $<10 \mathrm{~s}$

For physiological reasons, partly gravitational and part due to the intrinsic structure of the lung, neither ventilation nor DLNO is uniformly distributed. In a theoretical study of a two-compartment lung, PIIPER and SIKAND [51] showed that uneven distribution of inspired volume and DLCO/VA (equivalent to KCO) always lead to an underestimation of DLCO (and, by extension DLNO) compared to the homogeneous situation.

Dressel et al. [54] systematically studied the dependence of DLNO, DLCO and their components VA, KNO and $\mathrm{KCO}$ in normal subjects and patients with airflow obstruction due to cystic fibrosis. In normal subjects, the "accessible" VA was 3\% greater at a breath-hold time of $10 \mathrm{~s}$ than at $4 \mathrm{~s}$ (more time for gases to penetrate the alveoli if a $10 \mathrm{~s}$ breath-hold time is used), but that the KNO and DLNO were $\sim 14 \%$ less. The probable reason for the decrease in KNO and KCO with longer breath-hold times is that more weight is given, at longer breath-hold times, to more slowly filling and emptying units, whose DL/VA (equivalent to $K)$ is less than the faster units. In the normal subjects, there was a $9 \%$ decrease in DLCO from a $10 \mathrm{~s}$ breath-hold time compared to $4 \mathrm{~s}$ breath hold, so the DLNO/DLCO ratio was relatively unaffected. In airflow obstruction (cystic fibrosis), $V A$ at $10 \mathrm{~s}$ exceeded $V A$ at $4 \mathrm{~s}$ by $8 \%$, compared to the $3 \%$ increase in normal subjects. When comparing the $4-10$ s breath-hold time, the $14 \%$ decrease in DLNO and $18 \%$ decrease in KNO were similar in normal subjects and those with cystic fibrosis. But since the DLCO and KCO were less affected over the same time periods, the DLNO/DLCO ratio decreased by $15 \%$ in those with cystic fibrosis. These findings suggest that ventilation distribution, or inspired gas penetration, is heterogeneous, even in normal subjects, because a greater $V \mathrm{~A}$ occurs at $10 \mathrm{~s}$ versus $4 \mathrm{~s}$ breath hold; in contrast, heterogeneity increases $K \mathrm{NO}$ and $K \mathrm{CO}$ at $4 \mathrm{~s}$ versus $10 \mathrm{~s}$ by more than the change in $V \mathrm{~A}$, and this overcomes the smaller decrease in the 4-s VA. Thus, the net effects on DLNO and DLCO at $4 \mathrm{~s}$ versus $10 \mathrm{~s}$ breath-hold depend on the combination of opposing changes in $V \mathrm{~A}$ and $K \mathrm{NO}$ and $K \mathrm{CO}$, since $D \mathrm{~L}=K \times V \mathrm{~A}$.

Some studies show a different pattern. Studies in the early 1990s did not find a decrease in DLNO [53] or DLCO $[53,108]$ as breath-hold time increased, but the breath-hold times were short (down to $3 \mathrm{~s}$ breath hold) and the $K$ and $V$ A values were not reported, so no conclusion about the mechanism can be reached. In normal, healthy children, Thomas et al. [87] found that DLCO and VA were about equally increased at $10 \mathrm{~s}$ versus $5 \mathrm{~s}$ breath-hold time, and that KCO did not change significantly (DLNO was only studied at $5 \mathrm{~s}$ ). From the modelling studies of PIIPER and SIKAND [51], independence of breath-hold time implies homogeneous distribution of DLCO/VA (equivalent to KCO), which may be related to the smaller lung size (and less gravitational and iso-gravitational influences) in children.

\section{Evaluating the measurement of DLNO}

\section{Repeatability, reproducibility and number of tests}

It is necessary to report the intra- and inter-session variability of DLCO and DLNO measurements so that a distinction can be made between normal biological variability/technical variability of the measurement and a clinically measureable change in diffusing capacity. Table 3 presents both acceptable intra-session (within a given testing session) and inter-session (between sessions, or between days) variability for the $5 \mathrm{~s}$ breath-hold manoeuvre for DLNO and DLCO in absolute numbers $[48,49,88]$. An average value of two trials performed within 4-10 min of each other whose differences in DLNO and DLCO is within 17 and $3 \mathrm{~mL} \cdot \mathrm{min}^{-1} \cdot \mathrm{mmHg}^{-1}$, respectively, is acceptable in healthy subjects and those with pulmonary pathophysiology. The reproducibility in DLCO and DLNO that occurs week to week or month to month is 5 and $20 \mathrm{~mL} \cdot \mathrm{min}^{-1} \cdot \mathrm{mmHg}^{-1}$, respectively, in healthy subjects and those with pulmonary pathophysiology (table 3 ). That is, any diffusing capacity parameter that has a week-to-week change that is equal to or greater than the reproducibility has only a $5 \%$ chance that it is not a real change. For less stringent reproducibility criteria, where there's a $20 \%$ chance that the change in DLCO and DLNO that occurs week to week or month to month is not a real 
change, look at the "smallest measureable change" column in table 3. It is half the reproducibility. Refer to supplementary appendix $\mathrm{G}$ for the statistical calculations of repeatability and reproducibility.

There is a $15 \%$ difference between the reproducibility value for DLNO $\left(20 \mathrm{~mL} \cdot \mathrm{min}^{-1} \cdot \mathrm{mmHg}^{-1}\right)$ and the repeatability value for DLNO $\left(17.2 \mathrm{~mL} \cdot \mathrm{min}^{-1} \cdot \mathrm{mmHg}^{-1}\right)$. There is a $35 \%$ difference between the reproducibility value for DLCO $\left(4.9 \mathrm{~mL} \cdot \mathrm{min}^{-1} \cdot \mathrm{mmHg}^{-1}\right)$ and the repeatability value for DLCO $\left(3.2 \mathrm{~mL} \cdot \mathrm{min}^{-1} \cdot \mathrm{mmHg}^{-1}\right)$. However, the percentage difference is increased to $34 \%$ for DLCO (table 3 ). This suggests that DLNO is a more stable measure over months compared to DLCO and that the majority of the variability in DLNO is within-session and not between sessions [88].

Repeated tests do not affect DLNO within a given session, irrespective of COHb concentration [48, 49]. Even after 22 consecutive DLNO measurements, DLNO is unaffected, and the rise in methaemoglobin is minimal [48]. Since the largest slopes of the decrease in DLCO observed with rising COHb was $\sim 0.4-0.5 \mathrm{~mL} \cdot \mathrm{min}^{-1} \cdot \mathrm{mmHg}^{-1}$ decrease in DLCO per $1 \%$ increase in COHb (males and females combined) [48], the minimum number of repeated tests that would elicit a decrease in DLCO larger than its repeatability (i.e. $\geqslant 3.2 \mathrm{~mL} \cdot \mathrm{min}^{-1} \cdot \mathrm{mmHg}^{-1}$ ) would be eight for a $5 \mathrm{~s}$ breath-hold manoeuvre and six for a $10 \mathrm{~s}$ breath-hold manoeuvre. Thus, not more than eight $5 \mathrm{~s}$ breath-hold manoeuvres, or six $10 \mathrm{~s}$ breath-hold manoeuvres should be performed in a single session.

\section{Calculating DMco and Vc}

Using the simultaneous one-step NO-CO technique, measurements are made at a single alveolar $\mathrm{PO}_{2}$ level. Values for $\theta \mathrm{NO}$ and $\theta \mathrm{CO}$ are required in the calculations (table 4 and supplementary appendix E). The literature in relation to published values for $\theta \mathrm{NO}$ and $\theta \mathrm{CO}$ is reviewed in the earlier section Origins of DLNO. There is general consensus for using a finite $\theta \mathrm{NO}$ of $4.5 \mathrm{~mL} \mathrm{NO} \cdot\left(\mathrm{mL} \mathrm{blood} \cdot \mathrm{min}^{-1} \cdot \mathrm{mmHg}^{-1}\right)$ from CARLSEN and Comroe [29], which for clinical purposes is independent of alveolar $\mathrm{PO}_{2}$ or $\mathrm{Hb}$ concentration. Conversely, the whole-blood transfer conductance for carbon monoxide is dependent on mean capillary $\mathrm{PO}_{2}$ (approximately alveolar $\mathrm{PO}_{2}$ ) and $\mathrm{Hb}$ concentration (reflected in the haematocrit). Many equations for the 1/ $\theta$ CO relationship exist (i.e. table 5). We selected the 1/ 5 ) as the most representative. Negative values for DMCO cannot occur unless the DLNO/DLCO ratio is $>7.5$, which is very unlikely, since normal values for DLNO/DLCO range from 3.8 to 5.8 (table 1).

In the literature, several versions of the $1 / \theta \mathrm{CO}-\mathrm{PO}_{2}$ relationship (table 5) have been used in the calculation of DMCO and VC. The Roughton and Forster formula [11] yielded strong correlations between DLNO (as a surrogate for DMNO) and DMCO for experimental data at rest and at exercise [35, 36, 109]. Others (for example $[18,62,63,94])$ preferred the later formula given by FonsTER [4], but negative or excessively high DMCO values have been observed with its use [19]; thus, some [19, 25] favoured the formula given by ReEves and PARK [26] and "best fit" $\alpha$-ratios (all >2.0) for getting the best agreement for DMCO between

TABLE 4 Summary consensus statement for simultaneous single-breath measurement of diffusing capacities of the lung for nitric oxide $(D\llcorner N O)$ and carbon monoxide $(D\llcorner C O)$ in healthy adults

Issue Agreement

Breath-hold time

Measured inspired NO concentration Measured inspired $\mathrm{O}_{2}$ concentration Measured expired $\mathrm{O}_{2}$ concentration $1 / \theta \mathrm{CO}[16]$

$\theta$ NO $[14,29]$

\section{$\theta \mathrm{NO} / \mathrm{\theta CO}$ ratio}

DMco

Presentation of results
$10 \mathrm{~s}$ is desired for better gas mixing

4-6 $\mathrm{s}$ is acceptable if using a single electrochemical NO cell that measures in the ppm range 40-60 ppm, placed in the inspiratory bag $\leqslant 2$ min before use

Close to $21 \%$

Used to calculate $P_{\mathrm{AO}_{2}}$ and $\theta \mathrm{CO}$

(0.0062 $\cdot \mathrm{PAO}_{2}+1.16$ ) $\cdot$ (ideal $\mathrm{Hb} \div$ measured $\mathrm{Hb}$ )

$4.5 \mathrm{~mL} \mathrm{NO} \cdot(\mathrm{mL} \text { blood } \cdot \mathrm{min} \cdot \mathrm{mmHg})^{-1}$

$(1 / \theta \mathrm{NO}=0.222)^{\#}$

Average 8.01 (male $\mathrm{Hb} 14.6 \mathrm{~g} \cdot \mathrm{dL}^{-1}$ ), 8.73 (female $\mathrm{Hb} 13.4 \mathrm{~g} \cdot \mathrm{dL}^{-1}$ ) at $P_{\mathrm{AO}_{2}}$ of $100 \mathrm{mmHg}{ }^{\#}$

DMNO divided by $1.97^{\#}$

Report $D\llcorner N O, D\llcorner C O, K N O$ and $K c 0$ in absolute numbers and as \% predicted from regression equations (at the appropriate breath-hold time), with the corresponding LLN, ULN and z-score (standardised residuals: number of standard deviations above or below the reference value)

Report alveolar volume in L BTPS and as TLC \% pred

NO: nitric oxide; $\mathrm{O}_{2}$ : oxygen; $\theta \mathrm{CO}(\mathrm{NO})$ : specific conductance in the blood for carbon monoxide $(\mathrm{NO})$ in $\mathrm{mL} \cdot(\mathrm{mL} b l o o d \cdot \mathrm{min} \cdot \mathrm{mmHg})^{-1} ; D \mathrm{MCO}$ : alveolar-capillary membrane diffusing capacity for $\mathrm{CO}_{;} P_{2}$ : oxygen tension; $P_{\mathrm{AO}_{2}}$ : alveolar oxygen tension; $\mathrm{Hb}$ : haemoglobin; $D \mathrm{MNO}$ : alveolarcapillary membrane diffusing capacity for NO; KNO: rate of change of NO from alveolar gas; Kco: rate of change of CO from alveolar gas: LLN: lower limit of normal; ULN: upper limit of normal; BTPS: body temperature and pressure, saturated $\left(760 \mathrm{mmHg}, 37^{\circ} \mathrm{C}, 100 \%\right.$ humidity); TLC: total lung capacity. " : used in tables 1, 2 and 3 and the supplementary appendices. 
TABLE $51 / \theta C O$ equations that show reasonable agreement

Formula for $1 / \theta \mathrm{CO}$

\begin{tabular}{ccccc}
\multicolumn{2}{c}{$1 / \theta C O$} & & \multicolumn{2}{c}{$\theta N O / \theta C O$} \\
\cline { 1 - 1 } \cline { 5 - 6 } Ideal Hb & Ideal Hb & & Ideal Hb & Ideal Hb \\
$\left(14.6 \mathrm{~g} \cdot \mathrm{dL}^{-1}\right)$ & $\left(13.4 \mathrm{~g} \cdot \mathrm{dL}^{-1}\right)$ & & $\left(14.6 \mathrm{~g} \cdot \mathrm{dL}^{-1}\right)$ & $\left(13.4 \mathrm{~g} \cdot \mathrm{dL}^{-1}\right)$
\end{tabular}

Derived in vivo

GUÉNARD et al. [16]

$\left(0.0062 \cdot \mathrm{PAO}_{2}+1.16\right) \cdot($ ideal
$\mathrm{Hb} \div$ measured $\mathrm{Hb})$

Derived in vitro

FORSTER [4] $\alpha=\infty, \mathrm{pH}=7.4$

ROUghton and Forster [11] $\alpha=1.5, \mathrm{pH}=8.0$

HolLAND [28] $\alpha=1.5$
(0.0041. $\left.\mathrm{AO}_{2}+1.3\right) \cdot$ (ideal $\mathrm{Hb} \div$ measured $\mathrm{Hb}$ )

(0.0058. $\left.\mathrm{AAO}_{2}+1.0\right) \cdot$ (ideal $\mathrm{Hb} \div$ measured $\mathrm{Hb}$ )

(0.0065. $\left.\mathrm{AAO}_{2}+1.08\right) \cdot$ (ideal $\mathrm{Hb} \div$ measured $\mathrm{Hb}$ )
1.780

1.730
1.939

1.863

1.721

1.885
8.010

7.695

7.110

7.785
8.727

8.384

7.747

8.482

Numbers given are for the following standards: alveolar oxygen tension $\left(\mathrm{PAO}_{2}\right) 100 \mathrm{mmHg}$ and specific conductance in the blood for nitric oxide

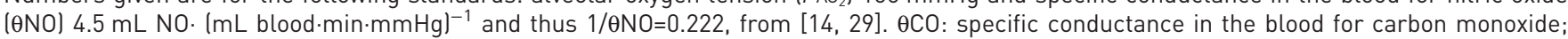
$\mathrm{Hb}$ : haemoglobin; $\alpha$ : the ratio of permeability of the red cell membrane to that of the red cell interior.

the one-step NO-CO technique, and the classical Roughton-Forster multistep alveolar $\mathrm{PO}_{2}$ method. GUÉNARD et al. [16] proposed a new $1 / \theta \mathrm{CO}-\mathrm{PO}_{2}$ formula empirically derived from single-breath measurements of DLNO and DLCO at two $\mathrm{PAO}_{2}$ levels while maintaining $\theta \mathrm{NO}$ at $4.5 \mathrm{~mL} \mathrm{NO} \cdot(\mathrm{mL}$ blood $\left.\cdot \mathrm{min}^{-1} \cdot \mathrm{mmHg}^{-1}\right)$. This formula potentially incorporates some of the physiological complexities lacking in earlier formulas derived using in vitro apparatus, but the agreement between calculations from the new and old formulas is reasonably close (table $5[4,11,28]$ ). Compared to the Forster formula [4] listed in table 5, the Guenard et al. 1/9CO formula (also in table 5) yields an average VC of $7 \%(5 \mathrm{~mL})$ greater $(95 \%$ limits of agreement $-5-11 \mathrm{~mL}$ ) and an average DMCO $\sim 6 \%$ lower (95\% limits of agreement $\left.-23-7 \mathrm{~mL} \cdot \mathrm{min} \cdot \mathrm{mmHg}^{-1}\right)$. Figure 4 demonstrates this graphically.

While in vivo factors could explain some of the differences between formulae, and an "optimal" $\theta \mathrm{CO}$ value under exercise or pathological conditions still remain to be determined, there are several formulae that show reasonable agreement (table 5). As $\theta \mathrm{CO}$ varies with $\mathrm{PAO}_{2}$, and there is a range of $\mathrm{PAO}_{2}$ even among normal subjects, expired oxygen concentration should be estimated wherever possible.

\section{Adjustment for $\mathrm{Hb}$ and $\mathrm{COHb}$}

In vitro $[14]$ and in vivo $[13,17]$ work indicates that no adjustment for $\mathrm{Hb}$ is needed for DLNO over the range of haematocrits encountered clinically [31]. However, for DLCO, adjustments should be made for $\mathrm{COHb}$ levels $>2 \%$, and for $\mathrm{Hb}$ levels that differ from the standard $\mathrm{Hb}$ concentration $\left(14.6 \mathrm{~g} \cdot \mathrm{dL}^{-1}\right.$ for adult males and $13.4 \mathrm{~g} \cdot \mathrm{dL}^{-1}$ for adult females) [84].

\section{Prediction equations \\ Methods}

Currently, there are several prediction equations for single-breath DLNO in adults: one from North America [107], one from North Africa [110] and two from Europe [57, 106]. Prediction equations were created for white, European or North American adults, since there were few Asian, black African and Indian subjects (all $<15$ cases) in these studies [57, 106, 107]. We obtained de-identified data from two of these studies which used a $5 \mathrm{~s}$ breath hold [106, 107]. Data from VAN DER LeE et al. [57] using a $10 \mathrm{~s}$ breath-hold time were also included in the analyses. We added $10 \mathrm{~s}$ breath-hold data from VAN DER LEE et al. since there is only a small $\sim 1 \mathrm{~mL} \cdot \mathrm{min}^{-1} \cdot \mathrm{mmHg}^{-1}$ absolute change in DLCO between 5 - and 10-s breath-hold times in healthy subjects at rest in those with low DLCO values, and a $\sim 3 \mathrm{~mL} \cdot \mathrm{min}^{-1} \cdot \mathrm{mmHg}^{-1}$ difference in those with high DLCO values [89]. These studies used a discrete sample of alveolar gas as opposed to continuous monitoring of exhaled gas concentrations.

From these datasets $[57,106,107]$, the DMCO and VC values were first re-calculated according to the formulas in supplementary appendices A-E, with the selected values for $\theta \mathrm{NO}$ and $\theta \mathrm{CO}$. Then a stepwise multiple linear regression procedure was used to determine which independent variable(s) best predicted nine dependent variables: DLCO and DLNo, DMCo and DMNO, VC, DLNo/DLCo ratio, DMCO/VA, VA, $V \mathrm{C} / V \mathrm{~A}, \mathrm{DMCO} / \mathrm{VC}, \mathrm{KCO}$ and $\mathrm{KNO}$. The independent variables entered into the model were age (years), age ${ }^{2}$, weight $(\mathrm{kg})$, height $(\mathrm{cm})$, sex $($ male $=1$, female $=0)$. An independent variable with an $\mathrm{R}^{2}$ change that 
accounted for $<5 \%$ of the total variance was eliminated from the model. When the full model accounted for $<25 \%$ of the total variance, it was not included in table 2 or the supplementary material.

Data were screened to identify outliers. Any data point that exceeded a standard deviation of the residuals $\geqslant 3.0$ on the first and second screening for each dependent variable were eliminated. The first screening verified that the standardised residuals had a constant variance by visualising a plot between the standardised residuals ( $y$-axis) and standardised predicted values ( $\mathrm{x}$-axis) to see if the values were consistently spread out, which would indicate normality and homoscedasticity. Linearity was analysed by creating a scatterplot matrix of the variables age, age ${ }^{2}$, weight and height. To examine multicolinearity, the variance inflation factor (VIF) was used to see whether there was a strong association between DLCO or DLNO and all the predictors in the model. All independent variables in the model must have a VIF $<10$. To examine whether the errors were autocorrelated, a Durbin-Watson test was performed. The range is $0-4$; a value of nearly 2 indicates non-autocorrelation, a value towards zero indicates a positive autocorrelation and a value close to 4 indicates a negative autocorrelation. To assess the prediction accuracy of the linear model, we randomly selected $90 \%$ of the subjects to fit a linear equation and then use the fitted linear equation to do the prediction for the remaining $10 \%$ of the subjects. This process was implemented for 1000 replicates, and we then reported the average correlation coefficient between each of the predicted values and the actual values obtained for $10 \%$ of the test subjects. In order to further check the accuracy of the measurement of alveolar volume from all three studies, we examined the predicted total lung capacity (using previous prediction equations [111]) and compared that to the predicted alveolar volume that was determined from the data obtained from three studies $[57,106,107]$.

Given that $5 \%$ of the population is defined to be outside of "normal", the lower limit of normal (LLN, 2.5th percentile) and upper limit of normal (ULN, 97.5th percentile) were calculated for each prediction equation (two-tailed criteria, z-score \pm 1.96 ). The association between DLNO and DLCO, and their relationship to VA was examined from this dataset. A type I probability level of 0.05 was used. Statistical analysis used SPSS (version 21.0; IBM SPSS Statistics, Chicago, IL, USA), verified using R version 3.2.0. (www.r-project.org/).

\section{Results}

535 healthy white subjects with a body mass index (BMI) $<30 \mathrm{~kg} \cdot \mathrm{m}^{-2}$ from three published studies [57, $106,107]$ were used. Barometric pressure varied slightly between studies, but was not a meaningful predictor. There were 45 outliers (standardised residuals $>3.0$ in the prediction models), so 490 subjects were used in the final analyses (table 1). Overall, the DLNO and DLCO z-scores for the 490 subjects were both $0.0 \pm 1.0$ with a skewness of 0.17 (DLNO) and 0.23 (DLCO). Mean \pm sD breath-hold time was $6.5 \pm 1.9 \mathrm{~s}$

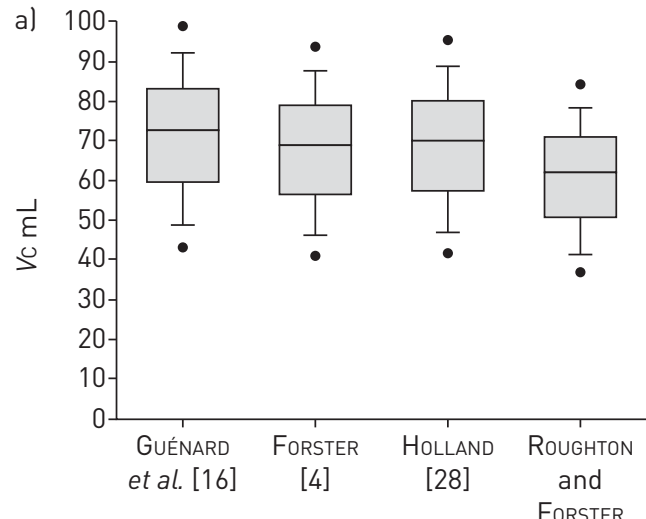

[11]

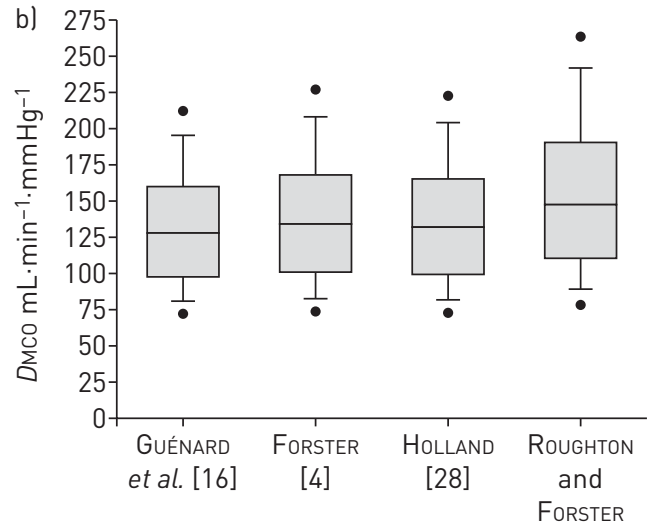

[11]

FIGURE 4 a) Pulmonary capillary blood volume (VC) and b) alveolar-capillary membrane diffusing capacity for carbon monoxide (DMCO), measured using four different formulas for specific conductance in the blood for carbon monoxide $(\theta \mathrm{CO})$. Based on the subject data from table 1, DMco and $V_{c}$ were calculated from the four formulas/constants listed in table 5 . The mean values for both Vc and DMco were statistically significant between all four formulas ( $p<0.01$ ). Each box represents the 25th (bottom border), 50th (middle) and 75th (top border) percentiles. The error bars above and below each box represent the 90th and 10th percentiles, respectively. The 5th and 95th percentiles are represented by solid black circles below and above the error bars, respectively. The formula from GuÉNARD et al. [16] provided the highest Vc and lowest overall DMco, while the formula from Roughton and Forster [11] provided the highest DMCO and lowest Vc. The three formulas developed by GUÉNARD et al. [16], FoRSTER [4] and HoLLAND [28] provided the closest mean values with one another. Taken overall, these formulas show reasonable agreement with one another. 
(range 4.6-10.0 s). While all DLCO gas mixtures reported in the studies displayed $21 \%$ oxygen in the tanks, the mean $\pm \mathrm{SD}$ inspired oxygen concentration and inspired $\mathrm{NO}$ concentration measured in the inspiratory bag was $19.5 \pm 0.7 \%$, (range 18.1-20.5\%) and $35 \pm 12 \mathrm{ppm}$ (range 6-65 ppm). The differences in breath-hold time between studies had a minimal influence in predicting any of the variables in table 2 ( $\leqslant 4 \%$ of the total variance). 117 (24\%) subjects were aged 18-29 years, 193 (39\%) subjects were aged 30-49 years, 132 (27\%) subjects were aged 50-69 years and 48 (10\%) subjects were aged $70-93$ years. $~ 33 \%$ of the subjects were classified as overweight (BMI $25.0-29.9 \mathrm{~kg} \cdot \mathrm{m}^{-2}$ ). 109 subjects were from the study by VAN DER LEE et al. [57], 115 subjects were from the study by ZaVORSKY et al. [107] and 266 subjects were from the dataset provided by AgUilaniu et al. [106]. The equations for DLNO and DLCO are presented in table 2. For DLCO and DLNO, height, age ${ }^{2}$ and sex explained $45 \%, 13 \%$ and $11 \%$ of the model, respectively. For DMCO and $D$ MNO, sex and age ${ }^{2}$ explained $41 \%$ and $19 \%$ of the model, respectively. For VC, height and age ${ }^{2}$ explained $36 \%$ and $14 \%$ of the model, respectively. For $V \mathrm{~A}$, height and sex explained $62 \%$ and $5 \%$ of the model, respectively. For $D \mathrm{MCO} / V \mathrm{~A}$, age ${ }^{2}$, sex and height explained $22 \%, 12 \%$ and $8 \%$ of the model, respectively. For KCO and KNO, age ${ }^{2}$ explained $34 \%$ and $39 \%$ of the model, respectively. The DLNO/DLCO ratio was $2 \%$ larger in males compared to females $(\mathrm{p}=0.013)$, which was not clinically or physiologically different (95\% CI of the difference $0.02-0.16$ units larger in males) with an overall mean $\pm \mathrm{SD} 4.79 \pm 0.40$. For $V \mathrm{C} / V \mathrm{~A}$ ratio, age ${ }^{2}$ and sex explained $19 \%$ and $8 \%$ of the model, respectively. As the predictive models for $D \mathrm{MCO} / V_{C}$ and the $D \mathrm{LNO} / D \mathrm{LCO}$ ratio each explained $<25 \%$ of the total variance, prediction equations were not developed for these parameters.

In terms of the prediction accuracy of the linear model, we found the following. For DLCO, DLNO, DMCO, VC, $V \mathrm{~A}, D \mathrm{MCO} / \mathrm{VA}$ ratio, $K \mathrm{CO}, \mathrm{KNO}$ and $\mathrm{VC} / V \mathrm{~A}$ ratio, the average correlation coefficients of the predicted values associated with the actual values were $0.82,0.83,0.78,0.69,0.82,0.64,0.57,0.63$ and 0.51 , respectively.

The mean predicted TLC was within $0.6 \%$ of the mean predicted alveolar volume for males (range $0.4-$ $0.8 \%$ ), and within $4 \%$ of the mean predicted alveolar volume for females (range 0-7\%). This suggests that Dlno, Dlco, DLno/Dlco, VA, KCO, KNO and DMCO/VA were less likely to be over- or underestimated, and the prediction equations are probably satisfactory.

DLNO and DLCO are strongly correlated (figure 2a, single breath). DLNO and DLCO correlate with VA $\left(\mathrm{R}^{2}\right.$ 0.64 and 0.62 , respectively) (figure $2 \mathrm{~b}$, single breath). These data are consistent with published $[35,109]$ and unpublished rebreathing data from Connie Hsia (personal communication) that DLCO is more tightly correlated with cardiac output compared to DLNO (figure 2c, rebreathing). The DLNO/DLCO ratio decreased by $0.05-0.08$ units for every $1.0 \mathrm{~L} \cdot \mathrm{min}^{-1}$ increase in cardiac output. Regression equation: DLNO to DLCO ratio $-0.061 \cdot\left(\right.$ cardiac output in $\left.\mathrm{L} \cdot \mathrm{min}^{-1}\right)+4.71, \mathrm{R}^{2}=0.16$, standard error of the estimate (SEE) $0.57, \mathrm{p}<0.001$ ).

The DMCO and VC calculations in tables 1-3 were performed according to the values prescribed in table 4 using the 1/ $\theta \mathrm{CO}$ formula derived from in vivo data by GUÉNARD et al. [16]. There are several other formulas for $1 / \theta C O$ which could change the predicted values for $V \mathrm{C}$ and DMCO (table 5). This ERS task force agrees that there may be other suitable formulas based on in vitro data (table 5). Nevertheless, we agree that using equations and constants provided in table 4 allow for clinical comparisons across studies. Based on human subject data from table 1, the 1/ $\theta$ CO formula from GUÉNARD et al. [16] provided the highest overall VC (by as much as $+11 \mathrm{~mL}$ or $17 \%, \mathrm{p}<0.01$ ) and lowest overall $\mathrm{DMCO}$ (by as low as $24 \mathrm{~mL} \cdot \mathrm{min}^{-1} \cdot \mathrm{mmHg}^{-1}$ or $15 \%$, $\mathrm{p}<0.01$; figure 4). In contrast, the lowest overall $V \mathrm{C}$ and highest overall DMCO was found with the $1 / \theta \mathrm{CO}$ formula from Roughton and Forster [11]. Holland [28], Forster [4] and Guénard et al. [16] provided mean DMCO and VC data that were within $5 \%$ of each other (figure 4 and table 5). As such, the formulas presented in table 5 show reasonable agreement with one another.

\section{Contraindications to DLNO and DLCO assessments}

There are no contraindications for DLNO and DLCO measurements other than patients who are unable to understand or collaborate to the procedure or unwilling to provide consent. Children aged $<18$ years are allowed to undergo DLNO and DLCO measurements, as are pregnant subjects [112].

\section{Future investigations}

There are three broad categories of research priorities in further development of the single-breath DLNO-DLCO technique: technology, physiology and clinical application.

\section{Technology}

Development of affordable, rapid-response chemiluminescence analysers with a resolution range from $<100 \mathrm{ppb}$ to $100 \mathrm{ppm}$ would be welcome. If electrochemical cells are used, the target resolution should be in the same range. 
Physiology

The calculations of DMCO, DMNO/DMCO ratio and VC from simultaneously measured DLNO and DLCO remain controversial. Considerable research supports CARLSEN and Comroe's [29] data that $\theta \mathrm{NO}$ is finite at $4.5 \mathrm{~mL}$ $\mathrm{NO} \cdot(\mathrm{mL} \text { blood.min } \cdot \mathrm{mmHg})^{-1}$. GUÉNARD et al.'s [16] 1/9CO equation is the only one that is derived from actual physiological measurements and the results agree reasonably well with several equations derived in vitro. More measurements of $\theta \mathrm{NO}$ and $\theta \mathrm{CO}$ using innovative techniques would be welcome. Little is known about physiological variation in $\theta \mathrm{NO}$ or $\theta \mathrm{CO}$ due to changes in $\mathrm{pH}$, the oxygen tension corresponding to $50 \%$ oxyhaemoglobin saturation $P_{50}$, temperature and 2,3-bisphosphoglycerate levels. Similarly, measurements of the $\mathrm{NO} / \mathrm{CO}$ diffusivity ratio (DMNO/DMCO) in lung tissue would be helpful. Whether the surface area relative to thickness of the diffusion barrier in the bronchial wall, or the lower than systemic pulmonary capillary haematocrit or the heterogeneous capillary erythrocyte distribution differentially alter DLNO and DLCO, and hence $D \mathrm{LNO} / D \mathrm{LCO}$ and $D \mathrm{MCO} / V_{\mathrm{C}}$ needs to be examined. Further studies are needed to define the relative response between DLNO and DLCO under a range of perturbations such as exercise and high-altitude exposure; these comparisons could yield mechanistic insight into alveolar microvascular recruitment. Comparison of single breath and rebreathing methods could offer insight into ventilatory heterogeneity.

\section{Clinical application}

Reference values of DLNO and DLNO/DLCO are lacking in non-Caucasian populations, and in relation to age. The relative impairment of DLCO and DLNO in disorders of the thorax, airway, parenchyma, vasculature and secondary to cardiac failure needs to be assessed. Whether the combination of DLNO, DLCO, DLNO/DLCO ratio, DMCO and VC will improve the management of cardiopulmonary diseases compared to the conventional use of DLCO remains to be determined.

\section{Summary and conclusions}

1) Recommendations for the standard single-breath DLCO technique [84] should be followed with exceptions for breath-hold time, inspiratory time, expiratory time and repeatability criteria.

2) NO analysers: the sensitivity and performance of $\mathrm{NO}$ electrochemical cells are less than ideal compared to the much more expensive chemiluminescence analyser. A lack of sensitivity has meant that breath-holding time has had to be reduced. Electrochemical NO cell analysers could continue to be used for the combined DLNO-DLCO measurement until more sensitive analysers at a more affordable price become available.

3) Breath-hold time: for users who have the less-sensitive electrochemical NO analysers, we agree on a breath-hold time of 4-6 s.

4) Inspired concentrations of $\mathrm{NO}, \mathrm{CO}$ and $\mathrm{O}_{2}$ should be as follows: $\mathrm{NO} 40-60 \mathrm{ppm}, \mathrm{CO} 0.3 \%$ and $\mathrm{O}_{2}$ close to $21 \%$. NO should be injected into the inspired bag $\leqslant 2 \mathrm{~min}$ before use, and the inspired concentrations of all these gases plus the inert tracer gas ( $\mathrm{He}, \mathrm{CH}_{4}$ and neon) must be recorded. After $120 \mathrm{~s}$ of non-use, the $\mathrm{NO}$ concentration will be reduced by $\sim 2.5 \mathrm{ppm}$ due to its conversion to $\mathrm{NO}_{2}$ [85].

5) Expired concentration of $\mathrm{O}_{2}$ : the exhaled "alveolar" $\mathrm{O}_{2}$ concentration should be measured so that $1 / \theta \mathrm{CO}$ can be estimated from the measurement.

6) Presentation of results: the DLNO and DLCO should be given in absolute numbers, as \% predicted from regression equations (at the appropriate breath-hold time) and with the LLN (mean -1.96-SEE) and the ULN (mean +1.96.SEE). In addition, the $\mathrm{z}$-score (standardised residuals: number of standard deviations above or below the reference value) should be presented. The same applies for KNO and KCO. Alveolar volume should be recorded in L BTPS and as TLC \% pred. The DLNO/DLCO ratio is a useful parameter, because it does not require choosing a physical constant $(\theta$ or $\alpha)$ in its calculation, and is relatively independent of breath-hold time, age, height and sex.

7) The calculations for DMCO and VC are provided in supplementary appendix E with a sample algorithm provided in appendix $\mathrm{H}$.

\section{References}

$1 \quad$ Borland C, Chamberlain A, Higenbottam T. The fate of inhaled nitric oxide. Clin Sci 1983; 65: 37P.

2 Borland C, Cracknell N, Higenbottam T. Is the measurment of "DLNO" a true measure of membrane diffusing capacity? Clin Sci 1984; 67: 41P.

3 Borland CDR. Nitric Oxide and Carbon Monoxide in Cigarette Smoke in the Development of Cardiorespiratory Disease in Smokers. Cambridge, University of Cambridge, 1988.

4 Forster RE. Diffusion of gases across the alveolar membrane. In: Fishman AP, Farhi LE, Tenney SM, eds. Handbook of Physiology, Section 3, The Respiratory System IV, Gas Exchange. Washington, DC, American Physiological Society, 1987; pp. 71-88.

5 Clutton-Brock J. Two cases of poisoning by contamination of nitrous oxide with higher oxides of nitrogen during anaesthesia. Br J Anaesth 1967; 39: 388-392.

6 Roe FJ. Certain aspects of the responses of laboratory rats to exposure to (a) nitrogen dioxide and (b) tobacco smoke. Tokai J Exp Clin Med 1985; 10: 363-369. 
Clough PN, Thrush BA. Mechanism of chemiluminescent reaction between nitric oxide and ozone. Trans Faraday Soc 1967; 63: 915-925.

8 Borland CDR, Chamberlain AT, Higenbottam TW, et al. Comparison between the rate of reaction of nitric oxide in the gas phase and in whole cigarette smoke. Beitr Tabakforsch 1985; 13: 67-73.

9 Borland C, Higenbottam T. Do the oxides of nitrogen in cigarette smoke cause emphysema in smokers? Tokai $J$ Exp Clin Med 1985; 10: 371-373.

10 Borland CD, Higenbottam TW. A simultaneous single breath measurement of pulmonary diffusing capacity with nitric oxide and carbon monoxide. Eur Respir J 1989; 2: 56-63.

11 Roughton FJ, Forster RE. Relative importance of diffusion and chemical reaction rates in determining rate of exchange of gases in the human lung, with special reference to true diffusing capacity of pulmonary membrane and volume of blood in the lung capillaries. J Appl Physiol 1957; 11: 290-302.

12 Guénard H, Varene N, Vaida P. Determination of lung capillary blood volume and membrane diffusing capacity in man by the measurements of NO and CO transfer. Respir Physiol 1987; 70: 113-120.

13 Borland CD, Dunningham H, Bottrill F, et al. Significant blood resistance to nitric oxide transfer in the lung J Appl Physiol 2010; 108: 1052-1060.

14 Borland $\mathrm{C}$, Bottrill F, Jones A, et al. The significant blood resistance to lung nitric oxide transfer lies within the red cell. J Appl Physiol 2014; 116: 32-41.

15 Borland CD, Cox Y. Effect of varying alveolar oxygen partial pressure on diffusing capacity for nitric oxide and carbon monoxide, membrane diffusing capacity and lung capillary blood volume. Clin Sci 1991; 81: 759-765.

16 Guénard HJ, Martinot JB, Martin S, et al. In vivo estimates of NO and CO conductance for haemoglobin and for lung transfer in humans. Respir Physiol Neurobiol 2016; 228: 1-8.

17 van der Lee I, Zanen $\mathrm{P}$, Biesma $\mathrm{DH}$, et al. The effect of red cell transfusion on nitric oxide diffusing capacity. Respiration 2005; 72: 512-516.

18 Taylor BJ, Coffman KE, Summerfield DT, et al. Pulmonary capillary reserve and exercise capacity at high altitude in healthy humans. Eur J Appl Physiol 2016; 116: 427-437.

19 Coffman KE, Taylor BJ, Carlson AR, et al. Optimizing the calculation of DM,CO and VC via the single breath single oxygen tension DLCO/NO method. Respir Physiol Neurobiol 2016; 221: 19-29.

20 Martinot JB, Guénard H, Dinh-Xuan AT, et al. Nitrogen monoxide and carbon monoxide transfer interpretation: state of the art. Clin Physiol Funct Imaging 2015 [In press DOI: 10.1111/cpf.12316].

21 Hughes JM, van der Lee I. The TL,NO/TL,CO ratio in pulmonary function test interpretation. Eur Respir J 2013 41: 453-461.

22 Gibson QH, Roughton FJ. The kinetics and equilibria of the reactions of nitric oxide with sheep haemoglobin J Physiol 1957; 136: 507-524.

23 Vaughn MW, Huang KT, Kuo L, et al. Erythrocytes possess an intrinsic barrier to nitric oxide consumption. J Biol Chem 2000; 275: 2342-2348.

24 Azarov I, Liu C, Reynolds H, et al. Mechanisms of slower nitric oxide uptake by red blood cells and other hemoglobin-containing vesicles. J Biol Chem 2011; 286: 33567-33579.

25 Ceridon ML, Beck KC, Olson TP, et al. Calculating alveolar capillary conductance and pulmonary capillary blood volume: comparing the multiple- and single-inspired oxygen tension methods. J Appl Physiol 2010; 109: 643-653. Reeves RB, Park HK. CO uptake kinetics of red cells and CO diffusing capacity. Respir Physiol 1992; 88: 1-21.

27 Hughes JM, Bates DV. Historical review: the carbon monoxide diffusing capacity (DLCO) and its membrane (DM) and red cell $\left(\theta \cdot V_{C}\right)$ components. Respir Physiol Neurobiol 2003; 138: 115-142.

28 Holland RA. Rate at which $\mathrm{CO}$ replaces $\mathrm{O}_{2}$ from $\mathrm{O}_{2} \mathrm{Hb}$ in red cells of different species. Respir Physiol 1969; 7: 43-63.

29 Carlsen E, Comroe JH Jr. The rate of uptake of carbon monoxide and of nitric oxide by normal human erythrocytes and experimentally produced spherocytes. J Gen Physiol 1958; 42: 83-107.

30 Borland C, Dunningham H, Bottrill F, et al. Can a membrane oxygenator be a model for lung NO and CO transfer? J Appl Physiol 2006; 100: 1527-1538.

31 Zavorsky GS. No red cell resistance to NO? I think not! J Appl Physiol 2010; 108: 1027-1029.

32 Hsia CC, Chuong CJ, Johnson RL Jr. Critique of conceptual basis of diffusing capacity estimates: a finite element analysis. J Appl Physiol 1995; 79: 1039-1047.

33 Hsia CC, Johnson RL Jr, Shah D. Red cell distribution and the recruitment of pulmonary diffusing capacity. J Appl Physiol 1999; 86: 1460-1467.

34 Wilhelm E, Battino R, Wilcock RJ. Low-pressure solubility of gases in liquid water. Chem Rev 1977; 77: $219-262$.

35 Phansalkar AR, Hanson CM, Shakir AR, et al. Nitric oxide diffusing capacity and alveolar microvascular recruitment in sarcoidosis. Am J Respir Crit Care Med 2004; 169: 1034-1040.

36 Tamhane RM, Johnson RL Jr, Hsia CC. Pulmonary membrane diffusing capacity and capillary blood volume measured during exercise from nitric oxide uptake. Chest 2001; 120: 1850-1856.

37 Hsia CC, Yan X, Dane DM, et al. Density-dependent reduction of nitric oxide diffusing capacity after pneumonectomy. J Appl Physiol 2003; 94: 1926-1932.

38 Paiva M, Engel LA. Pulmonary interdependence of gas transport. J Appl Physiol Respir Environ Exerc Physiol 1979; 47: 296-305

39 Linnarsson D, Hemmingsson TE, Frostell C, et al. Lung diffusing capacity for nitric oxide at lowered and raised ambient pressures. Respir Physiol Neurobiol 2013; 189: 552-557.

40 Zavorsky GS, Kim DJ, McGregor ER, et al. Pulmonary diffusing capacity for nitric oxide during exercise in morbid obesity. Obesity 2008; 16: 2431-2438.

41 Zavorsky GS, Quiron KB, Massarelli PS, et al. The relationship between single-breath diffusion capacity of the lung for nitric oxide and carbon monoxide during various exercise intensities. Chest 2004; 125: $1019-1027$.

42 Zavorsky GS, Beck KC, Cass LM, et al. Dynamic vs. fixed bag filling: impact on cardiac output rebreathing protocol. Respir Physiol Neurobiol 2010; 171: 22-30.

43 Asadi AK, Sá RC, Kim NH, et al. Inhaled nitric oxide alters the distribution of blood flow in the healthy human lung, suggesting active hypoxic pulmonary vasoconstriction in normoxia. J Appl Physiol 2015; 118: $331-343$.

44 Sheel AW, Edwards MR, Hunte GS, et al. Influence of inhaled nitric oxide on gas exchange during normoxic and hypoxic exercise in highly trained cyclists. J Appl Physiol 2001; 90: 926-932. 
Borland C, Cox Y, Higenbottam T. Measurement of exhaled nitric oxide in man. Thorax 1993; 48: 1160-1162 Alexanderson C, Olin AC, Dahlman-Höglund A, et al. Nasal nitric oxide in a random sample of adults and its relationship to sensitization, cat allergen, rhinitis, and ambient nitric oxide. Am J Rhinol Allergy 2012; 26: e99-e103.

Paredi P, Kharitonov SA, Meah S, et al. A novel approach to partition central and peripheral airway nitric oxide. Chest 2014; 145: 113-119.

Zavorsky GS. The rise in carboxyhemoglobin from repeated pulmonary diffusing capacity tests. Respir Physiol Neurobiol 2013; 186: 103-108.

Zavorsky GS, Murias JM. A small amount of inhaled nitric oxide does not increase lung diffusing capacity. Eur Respir J 2006; 27: 1251-1257.

Tsoukias NM, Dabdub D, Wilson AF, et al. Effect of alveolar volume and sequential filling on the diffusing capacity of the lungs: II. Experiment. Respir Physiol 2000; 120: 251-271.

Piiper J, Sikand RS. Determination of D-CO by the single breath method in inhomogeneous lungs: theory. Respir Physiol 1966; 1: 75-87.

Tsoukias NM, Wilson AF, George SC. Effect of alveolar volume and sequential filling on the diffusing capacity of the lungs: I. Theory. Respir Physiol 2000; 120: 231-249.

Moinard J, Guenard H. Determination of lung capillary blood volume and membrane diffusing capacity in patients with COLD using the NO-CO method. Eur Respir J 1990; 3: 318-322. on breath-hold time. Chest 2008; 133: 1149-1154

Cotton DJ, Newth CJ, Portner PM, et al. Measurement of single-breath CO diffusing capacity by continuous rapid CO analysis in man. J Appl Physiol Respir Environ Exerc Physiol 1979; 46: 1149-1156.

Roberts CM, MacRae KD, Seed WA. Multi-breath and single breath helium dilution lung volumes as a test of airway obstruction. Eur Respir J 1990; 3: 515-520.

van der Lee I, Zanen P, Stigter N, et al. Diffusing capacity for nitric oxide: reference values and dependence on alveolar volume. Respir Med 2007; 101: 1579-1584.

Hsia CC. Recruitment of lung diffusing capacity: update of concept and application. Chest 2002; 122: 1774-1783. physiological implications. J Physiol 2007; 582: 767-775.

Verbanck S, Kerckx Y, Schuermans D, et al. The effect of posture-induced changes in peripheral nitric oxide uptake on exhaled nitric oxide. J Appl Physiol 2009; 106: 1494-1498.

Rohdin M, Petersson J, Sundblad P, et al. Effects of gravity on lung diffusing capacity and cardiac output in prone and supine humans. J Appl Physiol 2003; 95: 3-10.

Borland C, Mist B, Zammit M, et al. Steady-state measurement of NO and CO lung diffusing capacity on moderate exercise in men. J Appl Physiol 2001; 90: 538-544.

Martinot JB, Mulè M, de Bisschop C, et al. Lung membrane conductance and capillary volume derived from the NO and CO transfer in high-altitude newcomers. J Appl Physiol 2013; 115: 157-166.

Groepenhoff $\mathrm{H}$, Overbeek MJ, Mulè M, et al. Exercise pathophysiology in patients with chronic mountain sickness exercise in chronic mountain sickness. Chest 2012; 142: 877-884.

Faoro V, Huez S, Vanderpool R, et al. Pulmonary circulation and gas exchange at exercise in Sherpas at high altitude. J Appl Physiol 2014; 116: 919-926.

van Ooij PJ, van Hulst RA, Houtkooper A, et al. Nitric oxide and carbon monoxide diffusing capacity after a 1-h oxygen dive to $9 \mathrm{~m}$ of sea water. Clin Physiol Funct Imaging 2014; 34: 199-208.

Dujić Z, Eterović D, Denoble P, et al. Lung diffusing capacity in a hyperbaric environment: assessment by a rebreathing technique. Br J Ind Med 1992; 49: 254-259.

Garbella E, Piarulli A, Fornai E, et al. Preliminary observations on the effect of hypoxic and hyperbaric stress on pulmonary gas exchange in breath-hold divers. Diving Hyperb Med 2011; 41: 97-100.

Shykoff BE. Pulmonary effects of submerged oxygen breathing: 4-, 6-, and 8-hour dives at $140 \mathrm{kPa}$. Undersea Hyperb Med 2005; 32: 351-361.

1994; 21: 235-243

Borland C, Cox Y, Higenbottam T. Reduction of pulmonary capillary blood volume in patients with severe unexplained pulmonary hypertension. Thorax 1996; 51: 855-856.

van der Lee I, Zanen P, Grutters JC, et al. Diffusing capacity for nitric oxide and carbon monoxide in patients with diffuse parenchymal lung disease and pulmonary arterial hypertension. Chest 2006; 129: 378-383.

Farha S, Laskowski D, George D, et al. Loss of alveolar membrane diffusing capacity and pulmonary capillary blood volume in pulmonary arterial hypertension. Respir Res 2013; 14: 6 .

Degano B, Mittaine M, Guénard H, et al. Nitric oxide and carbon monoxide lung transfer in patients with advanced liver cirrhosis. J Appl Physiol 2009; 107: 139-143.

Magini A, Apostolo A, Salvioni E, et al. Alveolar-capillary membrane diffusion measurement by nitric oxide inhalation in heart failure. Eur J Prev Cardiol 2015; 22: 206-212.

Zavorsky GS, Borland C. Confusion in reporting pulmonary diffusing capacity for nitric oxide and the alveolar-capillary membrane conductance for nitric oxide. Eur J Prev Cardiol 2015; 22: 312-313.

van der Lee I, Gietema HA, Zanen P, et al. Nitric oxide diffusing capacity versus spirometry in the early diagnosis of emphysema in smokers. Respir Med 2009; 103: 1892-1897.

Moinard J, Guenard H. Membrane diffusion of the lungs in patients with chronic renal failure. Eur Respir J 1993; 6: 225-230.

Zavorsky GS, Kim DJ, Sylvestre JL, et al. Alveolar-membrane diffusing capacity improves in the morbidly obese after bariatric surgery. Obes Surg 2008; 18: 256-263.

Dressel H, Filser L, Fischer R, et al. Lung diffusing capacity for nitric oxide and carbon monoxide in relation to morphological changes as assessed by computed tomography in patients with cystic fibrosis. BMC Pulm Med 2009; 9: 30 .

Barisione G, Bacigalupo A, Brusasco C, et al. Mechanisms for reduced pulmonary diffusing capacity in haematopoietic stem-cell transplantation recipients. Respir Physiol Neurobiol 2014; 194; 54-61. 
Graham BL, Dosman JA, Cotton DJ. A theoretical analysis of the single breath diffusing capacity for carbon monoxide. IEEE Trans Biomed Eng 1980; 27: 221-227.

Cotes JE, Chinn DJ, Quanjer PH, et al. Standardization of the measurement of transfer factor (diffusing capacity). Eur Respir J 1993; 6: Suppl. 16, 41-52.

Graham BL, Brusacso V, Burgos F, et al. 2017 ERS/ATS standards for single breath carbon monoxide uptake in the lung. Eur Respir J 2017; 49: 1600016

Fine DH. Critical evaluation of the Saltzman technique for NOx analysis in the $0-100 \mathrm{ppm}$ range. Environ Sci Technol 1972; 6: 348-350.

Jones RS, Meade F. A theoretical and experimental analysis of anomalies in the estimation of pulmonary diffusing capacity by the single breath method. Q J Exp Physiol Cogn Med Sci 1961; 46: 131-143.

Thomas A, Hanel B, Marott JL, et al. The single-breath diffusing capacity of CO and NO in healthy children of European descent. PLoS One 2014; 9: e113177.

Murias JM, Zavorsky GS. Short-term variability of nitric oxide diffusing capacity and its components. Respir Physiol Neurobiol 2007; 157: 316-325.

ensen RL, Teeter JG, England RD, et al. Sources of long-term variability in measurements of lung function: implications for interpretation and clinical trial design. Chest 2007; 132: 396-402.

$17-23$

Miller MR, Crapo R, Hankinson J, et al. General considerations for lung function testing. Eur Respir J 2005; 26 : $153-161$.

Zavorsky GS, Smoliga JM, Longo LD, et al. Increased carbon monoxide clearance during exercise in humans Med Sci Sports Exerc 2012; 44: 2118-2124.

Zavorsky GS, Lands LC. Lung diffusion capacity for nitric oxide and carbon monoxide is impaired similarly following short-term graded exercise. Nitric Oxide 2005; 12: 31-38.

Zavorsky GS, Milne EN, Lavorini F, et al. Small changes in lung function in runners with marathon-induced interstitial lung edema. Physiol Rep 2014; 2: e12056.

Sheel AW, Coutts KD, Potts JE, et al. The time course of pulmonary diffusing capacity for carbon monoxide following short duration high intensity exercise. Respir Physiol 1998; 111: 271-281.

Stewart IB, Potts JE, McKenzie DC, et al. Effect of body position on measurements of diffusion capacity after exercise. Br J Sports Med 2000; 34: 440-444.

Zavorsky GS, Milne EN, Lavorini F, et al. Interstitial lung edema triggered by marathon running. Respir Physio Neurobiol 2014; 190: 137-141.

Normand H, Lavigne F, Mouadil A. Performing the apnea of the single-breath carbon monoxide diffusing capacity: relaxation on the shutter or full inspiration with near atmospheric intrapulmonary pressure? Chest 2006; 130: $207-213$

Macintyre N, Crapo RO, Viegi G, et al. Standardisation of the single-breath determination of carbon monoxide uptake in the lung. Eur Respir J 2005; 26: 720-735.

Cinkotai FF, Thomson ML. Diurnal variation in pulmonary diffusing capacity for carbon monoxide. $J$ Appl Physiol 1966; 21: 539-542.

Respir Dis 1987; 136: 1381-1384.

Borland C, Cox Y. NO and CO transfer. Eur Respir J 1991; 4: 766.

Crapo RO, Kanner RE, Jensen RL, et al. Variability of the single-breath carbon monoxide transfer factor as a function of inspired oxygen pressure. Eur Respir J 1988; 1: 573-574.

Hughes JM, Pride NB. Examination of the carbon monoxide diffusing capacity $\left(\mathrm{DL}_{\mathrm{CO}}\right)$ in relation to its $K \mathrm{CO}$ and VA components. Am J Respir Crit Care Med 2012; 186: 132-139.

Krogh M. The diffusion of gases through the lungs of man. J Physiol 1915; 49: 271-300.

Aguilaniu B, Maitre J, Glénet S, et al. European reference equations for CO and NO lung transfer. Eur Respir J 2008; 31: 1091-1097. population. Nitric Oxide 2008; 18: 70-79. high-intensity exercise. J Sports Sci 1992; 10: 229-235.

Chance WW, Rhee C, Yilmaz C, et al. Diminished alveolar microvascular reserves in type 2 diabetes reflect systemic microangiopathy. Diabetes Care 2008; 31: 1596-1601.

Rouatbi S, Ben Saad H, Latiri I, et al. North-African reference values of alveolar membrane diffusion capacity and pulmonary capillary blood volume. Respiration 2010; 80: 301-312.

Quanjer PH, Tammeling GJ, Cotes JE, et al. Lung volumes and forced ventilatory flows. Report Working Party Standardization of Lung Function Tests, European Community for Steel and Coal. Official Statement of the European Respiratory Society. Eur Respir J 1993; 16: Suppl. 5-40.

2 Zavorsky GS, Blood AB, Power GG, et al. $\mathrm{CO}$ and NO pulmonary diffusing capacity during pregnancy: safety and diagnostic potential. Respir Physiol Neurobiol 2010; 170: 215-225.

Punjabi NM, Shade D, Wise RA. Correction of single-breath helium lung volumes in patients with airflow obstruction. Chest 1998; 114: 907-918.

Robson AG, Innes JA. Short term variability of single breath carbon monoxide transfer factor. Thorax 2001; 56 : $358-361$. 